LÍVIA MARIA CUNHA BUENO VILLARES DA COSTA

\title{
Personalidade e Adesão ao tratamento em pacientes adultos jovens portadores de HIV
}

Dissertação apresentada à Faculdade de Medicina da Universidade de São Paulo para obtenção do título de Mestre em Ciências.

Programa de Dermatologia.

Orientador: Prof. Dr. Jorge S. do Rosário Casseb 


\section{Lívia Maria Cunha Bueno Villares da Costa}

Personalidade e adesão ao tratamento em pacientes adultos jovens portadores de HIV

Dissertação apresentada à Faculdade de Medicina da Universidade de São Paulo para obtenção do título de Mestre em Ciências.

Programa de Dermatologia

Orientador: Prof. Dr. Jorge Simão do Rosário Casseb

São Paulo

2016 


\section{Dados Internacionais de Catalogação na Publicação (CIP)}

Preparada pela Biblioteca da

Faculdade de Medicina da Universidade de São Paulo

Creprodução autorizada pelo autor

Costa, Lívia Maria Cunha Bueno Villares da

Personalidade e adesão ao tratamento em pacientes adultos jovens portadores de HIV / Lívia Maria Cunha Bueno Villares da Costa. -- São Paulo, 2016.

Dissertação(mestrado)--Faculdade de Medicina da Universidade de São Paulo.

Programa de Dermatologia.

Orientador: Jorge Simão do Rosário Casseb.

Descritores: 1.HIV 2.Adesão à medicação 3.Terapêutica 4.Personalidade 5.Pacientes 6.Adulto jovem

USP/FM/DBD-025/16 


\section{DEDICATÓRIA}

A todos os pacientes do ambulatório ADEE 3002 que, ao longo destes anos de convivência, consederam-me a oportunidade de aprendizado e evolução, partilhando comigo suas histórias, sofrimentos e alegrias.

Agradeço por terem permitido que eu continuasse a realizar meu trabalho como psicóloga, encontrando cada vez mais sentido e utilidade em minha existência.

Somente graças a disponibilidade e coragem de todos eles foi possível concluir este estudo. 


\section{AGRADECIMENTOS}

Ao meu marido Luiz Guilherme, médico dedicado, cientista excepcional e a mente mais brilhante e inquieta que já conheci. Agradeço por todo Amor e compreensão ao longo destes anos.

A meus pais Marco Antônio e Maria Cecília, que sempre me ensinaram a valorizar o conhecimento e estudo, oferecendo-me a oportunidade de me tornar o melhor de mim.

A meu irmão Leandro, meu eterno companheiro e referência de Coragem.

A meu irmão Rodrigo, que mesmo antes de nascer, já nos ensinava o verdadeiro significado da palavra Perseverança.

Ao Dr. Jorge, meu amigo e orientador, pela oportunidade oferecida e por sempre acreditar em minhas ideias. Agradeço pelo conhecimento compartilhado, pela dedicação e paciência em me ensinar e por me acompanhar em cada passo durante esta fase de minha vida.

A Dra. Maria Rita, minha grande amiga, o presente que ganhei ao entrar no Hospital das Clínica pela primeira vez. Muito obrigado por estar comigo.

Aos meus grandes amigos do ambulatório ADEE 3002 e da clínica de Dermatologia que, sempre às terças-feiras, me recebiam com um sorriso no rosto, fazendo com que nossas tardes fossem repletas de ciência e alegria.

Aos funcionários da pós-graduação do Departamento de Dermatologia, Ruth, Márcia, Lucas e Marcelo, que sempre me trataram com muita atenção, incansáveis em solucionar minhas dúvidas, ajudando este trabalho a se tornar real.

Ao estatístico Raony Cassab, pelo verdadeiro interesse neste estudo e paciência inesgotável demonstrada em cada uma de nossas reuniões.

Aos meus amigos, todos eles, por estarem presentes em momentos importantes de minha vida, fazendo tudo ter sentido. Obrigada. 
Esta dissertação está de acordo com as seguintes normas, em vigor no momento desta publicação:

Referências: adaptado de International Committee of Medical Journals Editors (Vancouver).

Universidade de São Paulo. Faculdade de Medicina. Divisão de Biblioteca e Documentação. Guia de apresentação de dissertações, teses e monografias. Elaborado por Anneliese Carneiro da Cunha, Maria Julia de A. L. Freddi, Maria F. Crestana, Marinalva de Souza Aragão, Suely Campos Cardoso, Valéria Vilhena. $3^{\mathrm{a}}$ ed. São Paulo: Divisão de Biblioteca e Documentação, 2011.

Abreviaturas dos títulos dos periódicos de acordo com List of Journals Indexed in Index Medicus. 


\section{Sumário}

LISTA DE SIGLAS E ABREVIAÇÕES:

LISTA DE TABELAS

LISTA DE FIGURAS

RESUMO

ABSTRACT

1. INTRODUÇÃO: ................................................................................................... 1

2. HIPÓTESE: ..................................................................................................... 8

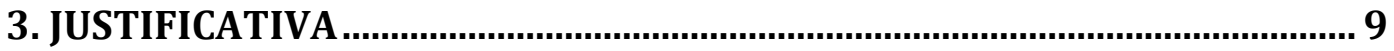

4. OBJETIVOS:

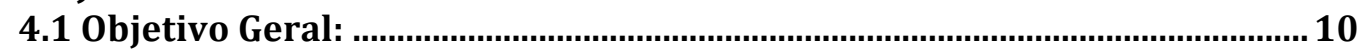

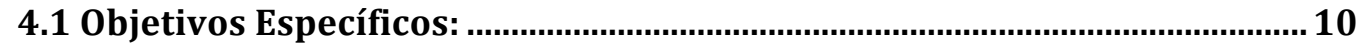

5. CASUÍSTICA E MÉTODOS..........................................................................11

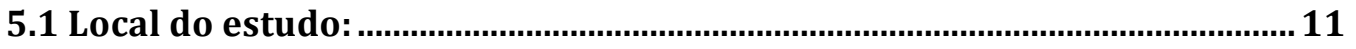

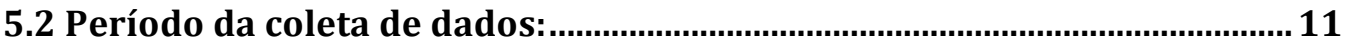

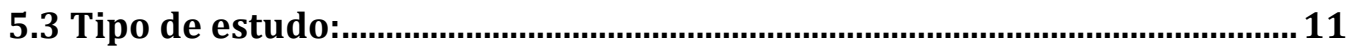

5.4 Amostragem e Análise estatística: .................................................................11

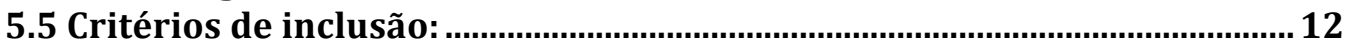

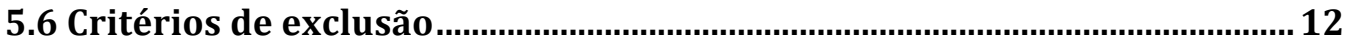

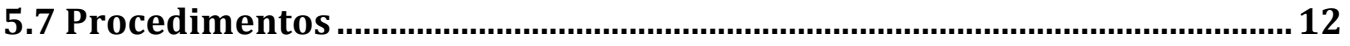

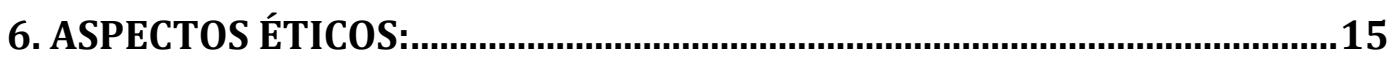

7. RESULTADOS

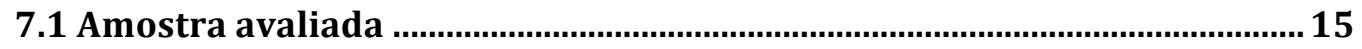

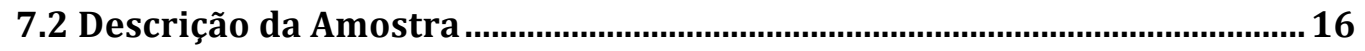

7.3 Análise por Grupo de Adesão ao Tratamento.................................................. 18

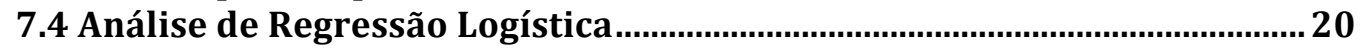

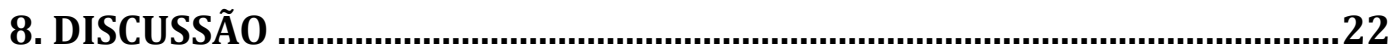

8.1 Divisão dos Grupos segundo grau de adesão: ...............................................22

8.2 Variáveis sócio-demográficas e Adesão ao tratamento: ..............................22

8.3 Fatores de Personalidade e Adesão ............................................................... 23

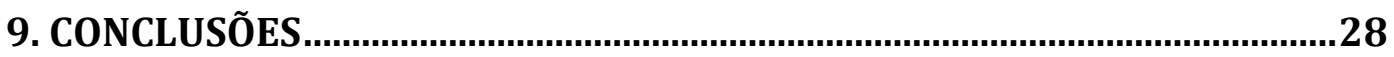

10. LIMITAÇÕES DO ESTUDO E PERSPECTIVAS: ........................................29

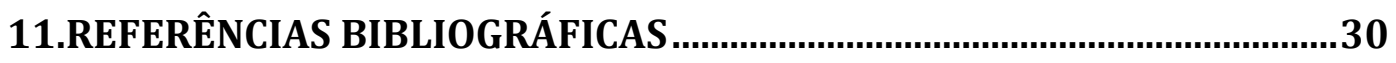

ANEXO I

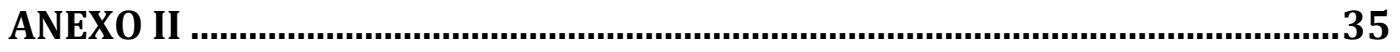

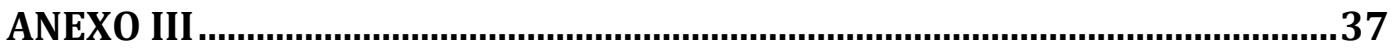

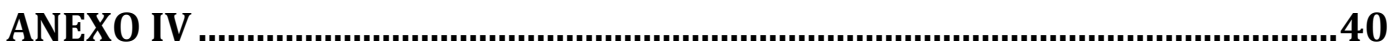

ANEXO V................................................................................................................41 


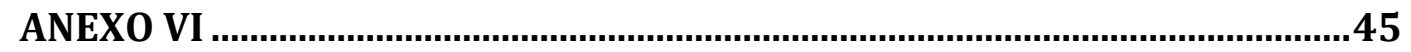

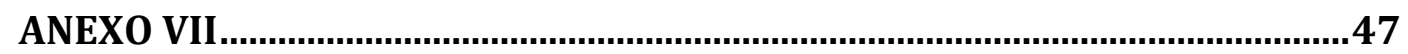

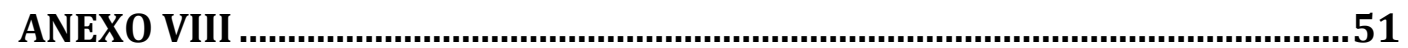




\section{LISTA DE SIGLAS E ABREVIAÇÕES:}

AIDS: Acquired immunodeficiency syndrome

ANOVA: Analysis of Variance

ASSIST: Alcohol, Smoking and Substance Involvement Screening Test

BFP: Bateria Fatorial de Personalidade

CEAT: Cuestionario para la Evaluación de la Adhesión al Tratamiento Antirretrovial

CD4: Cluster of Differentation 4

CAPPesq: Comitê de Avaliação de Ética em Pesquisa

CV: Carga viral

DST: Doença Sexualmente Transmissível

HIV: Human Immunodeficiency Virus

HSH: Homens que fazem sexo com homens

PCAP: Pesquisa de Conhecimento, Atitudes e Práticas na População Brasileira

SUS: Sistema Único de Saúde

TARV: Terapia Antirretroviral

TCLE: Termo de Consentimento Livre e Esclarecido 


\section{LISTA DE TABELAS}

Tabela 1: Descrição das variáveis categóricas.

Tabela 2: Descrição das variáveis quantitativas.

Tabela 3: Comparação das variáveis qualitativas com o CEAT (2 categorias) pelo teste de Fisher.......

Tabela 4: Comparação das variáveis quantitativas com o CEAT (2 categorias)

Tabela 5: Comparação das variáveis categóricas com o CEAT (3 categorias) pelo teste de Fisher.

Tabela 6: Comparação das variáveis quantitativas com a escala CEAT dicotômica

Tabela 7: Resultado da regressão logística com as escalas principais da BFP

Tabela 8: Resultado da regressão logística com as escalas principais da BFP, sem o paciente 14...

Tabela 9: Comparação da escala e subescalas de Neuroticismo com o CEAT (2 categorias).

Tabela 10: Comparação da escala e subescalas de Extroversão com o CEAT (2 categorias).....

Tabela 11: Comparação da escala e subescalas de Socialização com o CEAT (2 categorias)

Tabela 12: Comparação da escala e subescalas de Realização com o CEAT (2 categorias)

Tabela 13: Comparação da escala e subescalas de Abertura com o CEAT (2 categorias).

Tabela 14: Comparação da escala e subescalas de Neuroticismo com a escala CEAT padrão

Tabela 15: Comparação da escala e subescalas de Extroversão com a escala CEAT padrão.

Tabela 16: Comparação da escala e subescalas de Socialização com a escala CEAT padrão.

Tabela 17:Comparação da escala e subescalas de Realização com a escala CEAT padrão. 


\section{LISTA DE FIGURAS}

Figura 1: Gráfico de qualidade de ajuste da Regressão da Tabela 7 ................... 20

Figura 2: Gráfico de qualidade de ajuste da Regressão da Tabela 8..................... 21 


\section{RESUMO}

Costa LMCBV. Personalidade e adesão ao tratamento em pacientes adultos jovens portadores de HIV [Dissertação]. São Paulo: Faculdade de Medicina, Universidade de São Paulo; 2016.

Objetivos: Este trabalhado teve como objetivo avaliar a relação entre características de personalidade e adesão ao tratamento antirretroviral em pacientes jovens adultos (18 a 32 anos) portadores do HIV. Metodologia: A adesão ao tratamento foi avaliada pelo "Cuestionario para la Evaluación de la Adhesión al Tratamiento Antirretrovial (CEAT) e as características de personalidade foram avaliadas pela Bateria Fatorial de Personalidade (BFP). Resultados: A amostra foi composta por 51 pacientes e a análise dos dados sugere que o fator de personalidade associado a adesão ao tratamento é Realização. Este fator também surge como preditor independente para adesão ao tratamento. Discussão: Tais resultados reforçam a necessidade de inclusão destes aspectos na avaliação integral realizada pela equipe de saúde ao paciente jovem portador do vírus HIV. Os dados também reforçam a importância do profissional da área de psicologia como parte da equipe visto que, com o acompanhamento psicológico, é possível ajustar e modificar tais características, desenvolvendo estratégias de atendimento mais eficazes.

Descritores: HIV; adesão à medicação; terapêutica; personalidade; pacientes; adulto jovem. 


\begin{abstract}
Costa LMCBV. Personality and adherence to treatment in HIV-positive young adult patients [Dissertation]. São Paulo: "Faculdade de Medicina, Universidade de São Paulo"; 2016.
\end{abstract}

Objectives: This study aimed to evaluate the relation between personality characteristics and adherence to treatment in HIV-positive young adult patients (18 to 32 years old). Methods: The adherence to treatment was evaluated by the "Cuestionario para la Evaluación de la Adhesión al Tratamiento Antirretrovial" (CEAT) and the personality characteristics were evaluated by "Factorial Battery of Personality" (FBP). Results: The sample consisted of 51 patients and the analysis of data suggests that the personality factor associated with adherence is Conscientiousness. This factor was found to be independently associated with good adherence to treatment. Discussion: These results reinforce the need to include these aspects in the general evaluation by the health team. The data also reinforces the importance of a psychologist as part of the team. It is possible to adjust and modify personality characteristics through counseling, delivering a more effective care by improving adherence to treatment.

Descriptors: HIV; medication adherence; therapeutics; personality; patients; young adult. 


\section{INTRODUÇÃO:}

Os índices de contaminação pelo vírus HIV tem apresentado tendência de aumento no mundo todo, especialmente em países em desenvolvimento como o Brasil. Em 2014, estima-se que 36,9 milhões de pessoas vivam com HIV/aids, aproximadamente dois milhões de pessoas foram infectadas e 1.2 milhões de pessoas morreram de doenças relacionadas a aids (1).

No mesmo ano de 2014, de acordo com o último Boletim Epidemiológico aids/DST brasileiro de 2014, estima-se que 734 mil pessoas estejam vivendo com HIV/aids no país (2).

A maior concentração dos casos de aids no Brasil encontra-se nos indivíduos com idade entre 25 a 39 anos em ambos os sexos. De fato, observa-se um aumento estatisticamente significativo da taxa de detecção entre homens com 15 a 19 anos, 20 a 24 anos e 60 anos ou mais nos últimos dez anos. Portanto, os dados apontam que, embora os jovens tenham elevado conhecimento sobre prevenção da aids e outras doenças sexualmente transmissíveis, há tendência de crescimento na contaminação pelo vírus HIV (2).

A relação sexual prevalece como principal meio de contaminação entre os jovens maiores de 13 anos. Entre os homens, observa-se um predomínio da categoria de exposição heterossexual. Porém, nos últimos dez anos, há uma tendência de aumento na proporção de casos de homens que fazem sexo com homens (HSH), passando de 34,6\% em 2004 para 43,2\% em 2013. Ainda sobre HSH, observa-se uma tendência de aumento em quase todas as faixas etárias, exceto entre aqueles com 50 anos ou mais. Entre os homens com até 29 anos, a proporção mais que dobrou comparando-se 2004 com 2013. Na cidade de São Paulo, o número de casos de infeção pelo HIV triplicou em jovens do sexo masculino de 15 a 19 anos nos últimos dez anos (2004 a 2014) (2).

Em um levantamento realizado com 35 mil jovens de 17 a 20 anos, foi constatado que, em cinco anos, a prevalência do HIV nessa população passou de $0,09 \%$ para $0,12 \%$. A contaminação pelo HIV estava relacionada, principalmente, ao número de parceiros, à coinfecção com outras doenças sexualmente transmissíveis (DST) e às relações homossexuais masculinas (3).

A infecção pelo HIV em jovens parece estar bastante relacionada a exposição de risco. Em um estudo realizado com 36 mil jovens do sexo masculino, entre 17 e 22 anos 
de idade, constatou-se que 97\% deles sabiam que o melhor modo de prevenção a DST é o uso do preservativo (3). Comparando-se as Pesquisa de Conhecimentos, Atitudes e Práticas na População Brasileira (PCAP) de 2004 e 2008, observa-se que o uso regular do preservativo tem se reduzido: o uso do preservativo com parceiros casuais nos últimos 12 meses caiu de 58,4\% para 49,6\% e seu uso com qualquer parceiro caiu de $39 \%$ para $32,6 \%$.

O desenvolvimento de novas tecnologias e possibilidades na área da saúde trouxe avanço no tratamento para diferentes diagnósticos e tem aumentado o tempo de sobrevivência de pacientes com doenças crônicas, como a contaminação pelo HIV. Em dezembro de 2013, o Brasil tornou-se o primeiro país em desenvolvimento e o terceiro do mundo a recomendar o início imediato da Terapia Antirretroviral (TARV) para todas as pessoas portadoras do vírus, independentemente da contagem de células CD4, considerando a motivação do paciente para início do tratamento. Tal medida foi tomada visando tornar-se uma importante ação de saúde pública para o controle da transmissão do vírus (2) (4). Por isso a adesão ao tratamento tornou-se um novo desafio para as políticas públicas de DST/aids bem como para os serviços de saúde.

Compreende-se por adesão ao tratamento não somente o seguimento estrito das orientações médicas, mas também a compreensão do paciente sobre seu diagnóstico, sua maneira individual de lidar com sua situação de saúde e a concordância com o tratamento a ser seguido.

A adesão deve ser avaliada como um processo dinâmico com influência de múltiplos fatores (5). O paciente que não segue adequadamente a tomada da sua medicação, contribui para a criação de cepas virais multirresistentes e a consequente falência terapêutica. $\mathrm{O}$ desperdício do investimento na pesquisa e desenvolvimento de drogas acarreta prejuízos tanto no âmbito individual quanto no coletivo.

De acordo com o Manual de adesão para pessoas vivendo com HIV/aids (6), o ideal é que a adesão seja igual ou maior que 95\%. Alguns fatores que podem dificultar e prejudicar a adesão ao tratamento são a complexidade do regime terapêutico (número de comprimido, tamanho dos mesmos, diferentes horários das doses, forma de armazenamento), precariedade ou ausência de suporte social e afetivo e/ou percepção de tal suporte como insuficiente, baixa escolaridade, habilidades cognitivas insuficientes para lidar com o tratamento, não aceitação do diagnóstico, presença de transtornos mentais, efeitos colaterais da medicação, relação insatisfatória do usuário com equipe 
médica e multidisciplinar, crenças negativas e informações inadequadas a respeito da doença, abuso de álcool e outras drogas, entre outros.

Em relação aos fatores que podem influenciar a adesão adequada ao tratamento podemos citar conhecimento e compreensão corretos sobre a enfermidade e tratamento, bom vínculo com a equipe e o serviço de saúde, participação da equipe multidisciplinar no tratamento, parcerias com organizações da sociedade civil, apoio social e afetivo de qualidade (6).

Para avaliar o grau de adesão ao tratamento nos pacientes portadores do vírus HIV, o Questionário para a Avaliação da Adesão ao Tratamento Antirretroviral (CEAT) é bastante utilizado pelos profissionais da área da saúde. Este questionário foi desenvolvido na Espanha, entre 1999 e 2001, e atualmente foi validado e disponibilizado para utilização em seis línguas, inclusive o português. É um instrumento que avalia tanto aspectos relacionados a ingestão correta e assídua da medicação, bem como aspectos relacionados a auto-percepção do paciente e relação com equipe de saúde. Possui propriedades psicométricas capazes de mensurar com precisão e qualidade o grau de aderência ao tratamento antirretroviral (7) (8).

Mills et al (9), em uma revisão sistemática da literatura analisando 84 pesquisas qualitativas e quantitativas, investigaram facilidades e empecilhos a adesão a TARV em diferentes contextos socioeconômicos. Foi verificado que o uso abusivo de substâncias psicoativas, medo de descoberta do diagnóstico, esquecimento, ausência de compreensão dos benefícios do tratamento foram fatores que agiam como barreiras a adesão ao tratamento tanto em países desenvolvidos como naqueles em desenvolvimento. Limitações financeiras e dificuldades de acesso ao tratamento foram empecilhos a adesão nos países em desenvolvimento. Por outro lado, sentimentos de autovalorização, aceitação do diagnóstico e tratamento, percepção positiva sobre os mesmos, estratégias para lidar com o esquecimento e compreensão da importância de manter níveis elevados de adesão foram facilitadores em ambas as realidade (5) (9).

Resende et al (10) avaliaram a adesão ao tratamento antirretroviral em 129 pacientes vivendo com HIV/aids atendidos pelo Sistema Único de Saúde (SUS) em Alfenas-SP. Os dados obtidos apontaram uma baixa adesão ao tratamento em 37,2\% dos entrevistados. Pacientes do sexo masculino mostraram maiores percentuais em taxas de adesão estrita do que pacientes do sexo feminino. O estudo também mostrou associação entre grau de adesão e contagem de carga viral. 
Para a Organização Mundial da Saúde, o conceito de saúde não é apenas definido pela ausência de doenças, mas sim por um completo bem-estar físico, mental e social (11). Também é um processo dinâmico influenciado por questões físicas, culturais, sociais e psicológicas, portanto a personalidade de cada indivíduo é elemento fundamental na manutenção de boa qualidade em saúde. A eficácia do tratamento está ligada a mudanças de comportamento por parte do indivíduo, que tem um papel ativo em seu estilo de vida e cuidados (12).

A adesão ao tratamento, assim como qualquer outro tipo de comportamento individual, está intrinsicamente ligada a características de personalidade. Personalidade significa um conjunto de características, pensamentos e ações que guiam a vida dos indivíduos (13) (14). A personalidade integra diferentes funções psíquicas que estabelecem a forma pela qual o indivíduo reage ao meio em que vive (15). Ela orquestra a atribuição de significados ao mundo, aos objetos, as pessoas e a si mesmo.

Compreende-se que os comportamentos variam de pessoa para pessoa, porém existem aspectos chamados traços de personalidade que se mantêm constantes. Os traços de personalidade correspondem a características que indicam padrões de sentimentos, pensamentos e ações do indivíduo e procuram descrever e prever o comportamento humano (16).

Dentre os diversos modelos explicativos para os traços de Personalidade, podemos citar o modelo dos Cinco Grandes Fatores (CGF), que possui destaque por sua consistência empírica e replicabilidade. Este modelo origina-se de um grande conjunto de pesquisas na área de personalidade que se iniciaram na Inglaterra e Estados Unidos e vem sendo aprimoradas desde então. Baseia-se no modelo matemático de análise fatorial, que pressupõe que os traços humanos podem ser medidos por estudos correlacionais. Para o desenvolvimento deste modelo, primeiramente as características de personalidade dos indivíduos foram observadas e quantificadas. Em seguida, determinou-se quais variáveis estavam relacionadas entre si, calculando-se o coeficiente de correlação entre elas. A análise fatorial pode explicar um grande número de variáveis com um número menor de dimensões, ou seja, fatores. As correlações de cada variável individual com os fatores são denominadas cargas fatoriais, que possibilitam a interpretação de seus significados. Atualmente, muitas pesquisas vem sendo realizadas para verificar a replicabilidade do modelo em diferentes línguas e culturas e seus resultados apoiam a universalidade do modelo que engloba os seguintes aspectos da 
personalidade: Neuroticismo (neuroticism), Extroversão (extraversion), Abertura a experiências (openness to experience), Simpatia (agreableness) e Conscienciosidade (conscientiousness) (17) (15) (14).

A Bateria Fatorial de Personalidade (BFP) é um instrumento brasileiro que foi desenvolvido baseado no modelo dos Cinco Grande Fatores (14). Este modelo propõe que as pessoas possuem traços de personalidade e características que podem ser consideradas como predisposições a comportarem-se de determinado modo (18). Segundo o modelo, os traços de personalidade podem ser agrupados em cinco grandes dimensões explicativas, que agrupam características individuais de conteúdo semelhantes: Socialização, Realização, Extroversão, Neuroticismo e Abertura (16) (18).

O fator Socialização diz respeito a características de relacionamento interpessoal. Pessoas com alta pontuação em Socialização tendem a ser afetuosas, cooperativas, agradáveis e altruístas. Preocupam-se com os outros e agem de modo empático. As pessoas com baixos escores tendem a ser pessoas vingativas, manipuladoras, não cooperativas e irritáveis (19).

O grau de organização, persistência, controle e motivação para atingir metas dizem respeito ao fator Realização. Pessoas com altos escores neste fator tendem a ser confiáveis, pontuais, decididas, organizadas e perseverantes. Porém, as pessoas com baixos escores tendem a serem menos rígidas, sem clareza definida em seus objetivos, não confiáveis, descuidadas e negligentes (19).

Neuroticismo diz respeito ao ajustamento e instabilidade emocional e está ligado ao modo de lidar com conflitos e desconfortos psicológico. Escores elevados neste fator indicam vivência de sofrimento emocional, preocupações, melancolia e vergonha com mais intensidade. São pessoas com tendência a ansiedade, depressão, baixa tolerância a frustração e autocríticas. Em geral, escores baixos em Neuroticismo, indicam pessoas calmas e estáveis emocionalmente. Porém, Nunes et al (19), sugerem que baixas médias em Neuroticismo não significam necessariamente saúde mental e que os extremos se revelam como problemas neste fator.

O fator Abertura faz referência ao reconhecimento da importância de novas experiências e aos comportamentos exploratórios. Escores altos nesta dimensão indicam curiosidade, imaginação e criatividade e também experimentação ampla das emoções. Baixos escores indicam tendência ao convencional, dogmas e rigidez, sendo pessoas conservadoras e menos responsivas emocionalmente (19). 
Por fim, o fator Extroversão está relacionado as formas como as pessoas interagem com os demais e indica o quanto são comunicativas, ativas, responsáveis e gregárias. Pessoas com altos escores neste fator tendem a ser ativas, sociáveis, falantes, otimistas e afetuosas. Baixos escores indicam pessoas mais reservadas, sóbrias, indiferentes e quietas (19).

Atualmente, ainda há poucos trabalhos na literatura referentes a personalidade e adesão ao tratamento, principalmente relacionados a pacientes portadores do vírus HIV. Souza (20), em 2007, realizou um estudo do tipo caso-controle com 66 pacientes no intuito de avaliar fatores de personalidade que interferem na não adesão ao tratamento antirretroviral. Os fatores foram avaliados por meio de dois testes psicológicos: Escala Fatorial de Ajustamento Emocional/Neuroticismo e Figuras Complexas de Rey. O autor não conseguiu encontrar diferenças estatisticamente significantes entre os dois grupos, sugerindo que mais estudos fossem conduzidos devido a importância do tema para a saúde pública no Brasil.

Em relação ao tratamento de outros tipos de doenças, Axelsson et al (21) estudaram a influência da personalidade na adesão ao tratamento em pacientes com doenças crônicas. A análise estatística indicou que quanto maior o escore em Neuroticismo menor é o grau de adesão. Porém, Socialização e Realização foram correlacionados positivamente com adesão.

Axelsson et al (22) também avaliaram 268 jovens asmáticos para verificar a relação entre traços de personalidade, controle de asma, qualidade de vida e adesão ao tratamento. A Afetividade Negativa (faceta do fator Neuroticisimo) e a Impulsividade (faceta do fator Realização) correlacionaram-se negativamente com o controle da asma. A impulsividade também foi correlacionada negativamente com adesão em pacientes com uso de medicação constante. A Capacidade Hedônica (faceta do fator Extroversão) mostrou-se correlacionada com o controle da doença em mulheres.

Em outros estudos, Dobbles et al (23), em pesquisa com pacientes em lista de transplantes, verificaram que baixas pontuações no fator Realização indicavam não adesão a terapia imunossupressora menos de um ano após o transplante. $\mathrm{O}$ fator Realização foi considerado um preditor independente para não adesão a medicação.

Jerant et al (24) verificaram que o fator Neuroticismo estava associado a não adesão ao programa medicamentoso para prevenção de demência em idosos. 
A realização de pesquisas na área da saúde que auxiliem na compreensão de características de personalidade que exerçam influência sobre o desenvolvimento e tratamento de doenças faz-se extremamente necessária. O conhecimento destas características pode nortear a elaboração de estratégias preventivas focadas nas necessidades específicas de cada indivíduo (15). Diante da realidade de aumento da infeção pelo HIV em jovens, é importante o desenvolvimento e continuidade de ações que compreendam e estimulem a adesão ao tratamento, principalmente no paciente que ainda está no início da infecção. O desenvolvimento de estratégias adequadas de avaliação da adesão ao tratamento, atendimento eficaz, planejamento e execução de medidas terapêuticas e de reabilitação, aumenta a probabilidade de uma melhor qualidade de vida atenuando ou até revertendo alguns prejuízos psicológicos. 


\section{HIPÓTESE:}

A hipótese avaliada neste estudo é de que a adesão ao tratamento antirretroviral em pacientes adultos jovens portadores do vírus HIV é influenciada por características de personalidade dos mesmos. 


\section{JUSTIFICATIVA}

$\mathrm{O}$ número de indivíduos jovens infectados pelo HIV no mundo apresenta tendência, especialmente em países em desenvolvimento como o Brasil. Até 2030, estima-se que todos os portadores do vírus estarão em tratamento antirretroviral e que haverá uma redução de um milhão no número de mortes por doenças associadas a aids (25). Portanto, faz-se necessário o desenvolvimento de pesquisas que possam auxiliar na compreensão de fatores específicos que exerçam influência sobre a adesão ao tratamento antirretroviral. Como ainda existem poucos estudos na literatura focados especificamente em características de personalidade dos pacientes portadores de HIV este trabalho pode contribuir para a ampliação do olhar sobre adesão ao tratamento e apontar novos fatores que devam ser considerados ao elaborar estratégias de atendimento mais eficazes. 


\section{OBJETIVOS:}

\subsection{Objetivo Geral:}

Avaliar a existência de relação entre adesão ao tratamento para HIV/aids e traços de personalidade em pacientes adultos jovens (idade entre 18 e 32 anos).

\subsection{Objetivos Específicos:}

1. Avaliar o grau de adesão ao tratamento antirretroviral nos pacientes jovens da amostra, através do Questionário para a Avaliação da Adesão ao Tratamento Antirretroviral.

2. Avaliar os traços de personalidade destes pacientes, através da Bateria Fatorial de Personalidade.

3. Avaliar a existência de correlação entre adesão ao tratamento e características de personalidade.

4. Identificar fatores de personalidade que estejam agindo como preditores independentes para adesão ao tratamento. 


\section{CASUÍSTICA E MÉTOdOS}

\subsection{Local do estudo:}

Ambulatório ADEE 3002, pertencente ao Departamento de Dermatologia do Hospital das Clínicas da Faculdade de Medicina da Universidade de São Paulo. Recebe pacientes provenientes do Banco de Sangue do hospital.

\subsection{Período da coleta de dados:}

Agosto/2014 - Agosto/2015

\subsection{Tipo de estudo:}

Estudo transversal, abordagem quantitativa, com coleta de dados mista e eixo analítico prospectivo.

\subsection{Amostragem e Análise estatística:}

Amostra de conveniência por entrada sequencial. Durante doze meses, foram avaliados todos os pacientes que compareceram ao ambulatório e que se encaixavam nos critérios de inclusão da pesquisa, concordando em participar da mesma.

Optou-se por realizar um estudo piloto com 43 pacientes para calcular o poder amostral. Foi utilizado o teste ANOVA, com nível de confiança de $95 \%$ e poder do teste de $80 \%$. Utilizou-se o desvio padrão de 0,83 (desvio da própria amostra referente aos dados da BFP), assumindo a divisão dos sujeitos em 3 grupos: não aderente, boa adesão e adesão estrita. De acordo com este cálculo, 60 pacientes foram elegíveis para o estudo.

A análise estatística dos dados dividiu-se em três módulos: análise descritiva, análise bivariada e regressão logística.

A análise descritiva foi feita por medidas resumo usuais como média e desvio padrão (DP), mediana e mínimo (mín) e máximo (máx). O teste de Anderson-Darling (26) foi utilizado para verificar se os dados eram normalmente distribuídos, tornando o uso de testes paramétricos (teste t e ANOVA) mais adequados. Nos casos em que o teste de Anderson-Darling rejeitou a normalidade foram utilizados testes não paramétricos (Mann-Witney, Levene, Kruskal-Wallis e Tukey não paramétrico) (27).

Para a análise das associações entre adesão e as escalas da foram realizados dois modelos de regressão logística (28). O primeiro modelo incluiu as subfatores da BFP e o segundo modelo incluiu os fatores principais. Em ambos os modelos foi feita a 
seleção de variáveis pelo método de backward com critério (alfa) de saída de 0,10 e foi feito o gráfico de envelope, para verificar a qualidade de ajuste do modelo. O software utilizado para análises foi o R 3.1.2. e o nível de significância adotado nas análises foi de 0,05 .

\subsection{Critérios de inclusão:}

- Pacientes portadores do vírus HIV.

- Idade entre 18 e 32 anos.

- Indicação terapêutica para uso de TARV.

- Escolaridade mínima de quatro anos.

\subsection{Critérios de exclusão}

- Incapacidade para compreender os conteúdos necessários para a avaliação e aplicação dos testes.

- Diagnóstico concomitante de doenças neurológicas oportunistas em atividade.

- Pacientes co-infectados.

- Uso de substâncias psicoativas.

- Ausência de consentimento para participar do estudo.

\subsection{Procedimentos}

Após assinatura do Termo de Consentimento Livre e Esclarecido (Anexo III), as informações demográficas e clínicas foram obtidas por meio de uma entrevista, utilizando-se um questionário estruturado (Anexo IV).

Para rastreio e avaliação do uso de substâncias psicoativas foi utilizado o teste de triagem do envolvimento com álcool, tabaco e outras substâncias ASSIST - Alcohol, Smoking and Substance Involvement Screening Test (Anexo V). O teste é composto por oito questões sobre o uso de substâncias psicoativas. As questões abordam a frequência e problemas relacionados ao uso, preocupação de pessoas próximas ao usuário, prejuízo na execução de tarefas, tentativas mal sucedidas de cessar ou reduzir o uso, sentimento de compulsão, entre outros. Cada resposta pode ter um valor de 0 a 4 , sendo que a soma total varia entre 0 a 20 . Considera-se a faixa de escore de 0 a 3 como indicativa de uso ocasional, de 4 a 15 como indicativa de abuso e maior ou igual a 16, como sugestiva de dependência. Foi utilizada a versão em português do ASSIST (29). 
Para avaliação de personalidade foi utilizada a Bateria Fatorial de Personalidade (Anexo VII), um instrumento psicológico de avaliação construído a partir do modelo dos Cinco Grandes Fatores, que inclui as dimensões Extroversão, Socialização, Realização, Neuroticismo e a Abertura (19). Para a elaboração da bateria foram examinadas várias referências sobre os Cinco Grandes Fatores, o que possibilitou listar os traços de personalidade que deveriam ser representados pelos itens criados para avaliar cada uma das dimensões. O DSM-IV (30) também foi uma importante fonte de informações para a construção dos itens, especificamente a seção que apresenta os transtornos de personalidade; pois foram geradas hipóteses de associação de escores baixos ou altos em cada um dos cinco fatores com os transtornos descritos. No intuito de contemplar alguns aspectos descritos na literatura internacional a respeito dos Cinco Grandes Fatores foi utilizado o projeto internacional de pesquisa em personalidade, International Personality Item Pool, elaborado para promover um rápido acesso a medidas de diferenças individuais a serem desenvolvidas em conjunto com cientistas do mundo todo. Durante a elaboração da bateria foram realizadas análises semânticas e psicométricas e a versão preliminar da bateria era constituída por 167 itens, e a versão final composta por 126. A bateria foi desenvolvida no Brasil, considerando valores culturais, diversidades regionais e especificidades dos quadros clínicos na nossa realidade. É composta por frases avaliadas por uma escala tipo Likert de sete pontos, que indica o nível de identificação das pessoas com características descritas nos mesmos. Dezoito estudos independentes compuseram a análise da dimensionalidade da BFP, totalizando dados de 6.599 pessoas em todo o Brasil. Em relação a confiabilidade do questionário, a precisão medida por Alfa de Cronbach para cada um dos itens prinipais foi a seguinte: Neuroticisimo - 0,89; Extroversão - 0,84; Socialização - 0,85; Realização - 0,83 e Abertura - 0,74. 
Os itens avaliados pela Bateria Fatorial de Personalidade são:

\begin{tabular}{|c|c|c|c|c|}
\hline Neuroticismo & Abertura & Socialização & Realização & Extroversão \\
\hline $\begin{array}{ll} & \text { Vulnerabilidade } \\
\text { - } & \text { Instabilidade } \\
\text { - } & \text { Passividade } \\
\text { - } & \text { Depressão }\end{array}$ & $\begin{array}{ll}\text { - } & \text { Abertura a ideias } \\
\text { - } & \text { Liberalismo } \\
\text { - } & \text { Busca/novidades }\end{array}$ & $\begin{array}{ll}\cdot & \text { Amabilidade } \\
\text { - } & \text { Pró-sociabilidade } \\
\text { - } & \text { Confiança }\end{array}$ & $\begin{array}{ll}\text { - } & \text { Competência } \\
\text { - } & \text { Ponderação } \\
\text { - } & \text { Empenho }\end{array}$ & $\begin{array}{ll}\text { - } & \text { Nível de Comunicação } \\
\text { - } & \text { Altivez } \\
\text { - } & \text { Dinamismo/ } \\
& \text { Assertividade } \\
\text { - } & \text { Interações Sociais }\end{array}$ \\
\hline
\end{tabular}

Por fim, a avaliação de adesão ao tratamento foi realizada pela aplicação do "Cuestionario para Evaluación de la Adhesión al Tratamiento Antirretrovial" (Anexo VI), traduzido, adaptado e validado para a língua e população brasileira. É um instrumento auto-informe composto por vinte perguntas. Possui caráter multidimensional, pois avalia os principais fatores que podem modular $\mathrm{o}$ comportamento de adesão ao tratamento. As pontuações variam de 1 a 5 . As seguintes faixas de pontuação foram consideradas: adesão baixa/insuficiente: pontuação total menor ou igual a 74; adesão boa/adequada: pontuação total entre 75 e 79; adesão estrita: pontuação maior ou igual a 80 (7). 


\section{ASPECTOS ÉTICOS:}

Este estudo foi submetido a avaliação e aprovação da Comissão de Ética para Análise de Projetos de Pesquisa (CAPPesq) sob registro online 11435 e número do parecer 673.917 (Anexo VIII).

No Termo de Consentimento Livre e Esclarecido (TCLE) constavam os objetivos do estudo e os instrumentos utilizados e a aplicação dos mesmos só era realizada após a assinatura do termo pelo participante. O participante também era informado que poderia solicitar sua exclusão da pesquisa a qualquer momento, sem prejuízo do atendimento no ambulatório.

O anonimato dos participantes e o sigilo em relação aos dados coletados são mantidos e todos aqueles que necessitavam de atendimento mais específico foram encaminhados para profissional da equipe de saúde. Os resultados do testes de adesão e personalidade eram enviados aos participantes por e-mail e era oferecido a eles a oportunidade de conversar sobre os mesmos com a pesquisadora, em atendimento psicológico agendado no ambulatório.

\section{RESULTADOS}

\subsection{Amostra avaliada}

A amostra foi composta por 51 pacientes, a maior parte por homens (76,47\%), o mecanismo de transmissão mais frequente foi a via sexual $(76,47 \%)$ e a maioria possuía nível de educação superior (70,58\%). A idade média foi de 25 anos e o tempo médio de infecção foi de 7 anos. Em relação a adesão ao tratamento, 37 pacientes apresentaram boa adesão/adesão estrita (72,5\%) e 14 pacientes apresentaram baixa adesão (27,5\%).

Sobre os principais fatores da Bateria Fatorial de Personalidade seguem os resultados: Neuroticismo média 3,65 e DP 1,07; Extroversão média 4,69 e DP 0,97; Socialização média de 5,17 e DP 0,68; Realização média de 5,1 e DP 0,77; Abertura média de 5,02 e DP 0,95. 


\subsection{Descrição da Amostra}

As Tabelas 1 e 2 descrevem a amostra total de 51 pacientes. Na Tabela 1 essa descrição é feita via frequência e porcentagem de casos em cada uma das categorias. $\mathrm{Na}$ Tabela 2 a descrição é feita por duplas, média/desvio padrão e mediana/máximo e mínimo.

Tabela 1: Descrição das variáveis categóricas.

\begin{tabular}{cccc}
\hline Variável & Categoria & $\mathrm{n}$ & $\%$ \\
\hline Gênero & $\mathrm{F}$ & 12 & 23,53 \\
Mec. Transmissão & $\mathrm{M}$ & 39 & 76,47 \\
& desconhecido & 4 & 7,84 \\
& sexual & 39 & 76,47 \\
Carga Viral & vertical & 8 & 15,69 \\
& Indetectável & 34 & 66,67 \\
Nível Educacional & Detectável & 17 & 33,33 \\
& Fundamental & 1 & 1,96 \\
& Médio & 13 & 25,49 \\
& Superior & 36 & 70,58 \\
& Pós-graduação & 1 & 1,96 \\
\hline
\end{tabular}


Tabela 2: Descrição das variáveis quantitativas.

\begin{tabular}{ccc}
\hline Variável & Media (DP) & Mediana (mín-max) \\
\hline Idade & $25,53(3,99)$ & $26(18-32)$ \\
Tempo de infeç̧ão(anos) & $7,12(7,46)$ & $4(0,16-26)$ \\
Neuroticisimo & $3,65(1,07)$ & $3,77(1,64-5,7)$ \\
Vulnerabilidade & $3,76(1,4)$ & $3,67(1,11-6,33)$ \\
Instabilidade & $4,25(1,34)$ & $4,5(1,67-7)$ \\
Passividade & $3,89(1,43)$ & $4(1-6,67)$ \\
Depressão & $2,76(1,29)$ & $2,5(1-6,38)$ \\
Extroversão & $4,69(0,97)$ & $4,87(2,35-6,66)$ \\
Nível de Comunicação & $4,29(1,3)$ & $4,33(1,33-6,83)$ \\
Altivez & $4,22(1,16)$ & $4,14(1,86-6,71)$ \\
Dinamismo & $5,03(1,19)$ & $4,8(3-7)$ \\
Interações Sociais & $5,21(1,15)$ & $5,43(2,29-7)$ \\
Socialização & $5,17(0,68)$ & $5,28(2,89-6,86)$ \\
Amabilidade & $5,9(0,65)$ & $6(4-6,92)$ \\
Pró Sociabilidade & $5,33(1,09)$ & $5,5(2,5-7)$ \\
Confiança & $4,29(1,08)$ & $4,25(1,25-7)$ \\
Realização & $5,1(0,77)$ & $5,11(2,96-6,51)$ \\
Competência & $5,37(0,96)$ & $5,4(3,6-7)$ \\
Ponderação & $4,74(1,45)$ & $5(1-7)$ \\
Empenho & $5,2(0,95)$ & $5,14(2,86-7)$ \\
Abertura & $5,02(0,8)$ & $5,06(3,06-6,69)$ \\
Abertura a ideias & $5,08(1,01)$ & $5(2,4-6,7)$ \\
Liberalismo & $5,31(0,93)$ & $5,29(3,29-7)$ \\
Busca por novidades & $4,7(1,03)$ & $4,83(2,5-6,67)$ \\
\hline & & \\
\hline & & \\
\hline
\end{tabular}




\subsection{Análise por Grupo de Adesão ao Tratamento}

Foi realizada uma comparação entre variáveis categóricas e quantitativas e a escala CEAT dividida em dois grupos: boa adesão (adesão estrita + boa adesão) e baixa adesão. Três variáveis obtiveram um p-valor menor ou igual a 0.10 , indicando tendências importantes: Realização, Ponderação e Empenho (Anexo I).

Tabela 3: Comparação das variáveis qualitativas com o CEAT (2 categorias) pelo teste de Fisher

\begin{tabular}{|c|c|c|c|c|c|c|}
\hline \multirow{2}{*}{ Fator } & \multirow{2}{*}{ Categoria } & \multicolumn{2}{|c|}{ CEAT: boa adesão $(n=37)$} & \multicolumn{2}{|c|}{ CEAT: pouco aderente $(n=14)$} & \multirow{2}{*}{ p-valor } \\
\hline & & $\mathrm{n}$ & $\%$ & $\mathrm{n}$ & $\%$ & \\
\hline \multirow[t]{2}{*}{ Gênero } & $\mathrm{F}$ & 9 & 24,32 & 3 & 21,43 & 1 \\
\hline & M & 28 & 75,68 & 11 & 78,57 & \\
\hline \multirow[t]{2}{*}{ Mec. Transmissão* } & sexual & 29 & 82,86 & 10 & 83,33 & 1 \\
\hline & vertical & 6 & 17,14 & 2 & 16,67 & \\
\hline \multirow[t]{2}{*}{ Carga viral } & Indetectável & 27 & 72,97 & 7 & 50 & 0,183 \\
\hline & Detectável & 10 & 27,03 & 7 & 50 & \\
\hline \multirow[t]{4}{*}{ Nível Educacional } & Fundamental completo & 0 & 0 & 1 & 7,14 & 0,706 \\
\hline & Ensino Médio & 10 & 27,02 & 3 & 21,43 & \\
\hline & Ensino Superior & 26 & 70,28 & 10 & 71,43 & \\
\hline & Pós-graduação & 1 & 2,7 & 0 & 0 & \\
\hline
\end{tabular}

*Mecanismo de transmissão não considera os desconhecidos para a análise (boa adesão $n=35$ e pouco aderente $n=12)$.

Tabela 4: Comparação das variáveis quantitativas com o CEAT (2 categorias)

\begin{tabular}{cccccccc}
\hline \multirow{2}{*}{ Variável } & \multicolumn{2}{c}{ CEAT: boa adesão $(n=37)$} & \multicolumn{2}{c}{ CEAT: pouco aderente $(\mathrm{n}=14)$} & \multirow{2}{*}{ Teste } & $\mathrm{p}$-valor \\
\cline { 2 - 5 } & Media (DP) & Mediana (mín-max) & Media (DP) & Mediana (mín-max) & & \\
\hline Idade & $25,14(4,2)$ & $25(18-32)$ & $26,57(3,27)$ & $27(21-31)$ & $\mathrm{t}$ & 0,207 \\
Tempo de infecção (anos) & $6,48(7,18)$ & $3(0,16-26)$ & $8,8(8,19)$ & $6,5(0,16-26)$ & Mann-Whitney & 0,271 \\
\hline
\end{tabular}


Também foram realizadas análises dividindo os pacientes em três grupos segundo os resultados do CEAT: aderente estrito, boa adesão e pouca adesão. Os resultados destas análises aparentam ser menos robustos que os das análises anteriores devido ao baixo número de pacientes em cada um dos grupos. A variável Abertura a Ideias não possui distribuições semelhantes entre os três grupos (teste de homogeneidade das variâncias de Levene) e, por isso, foi verificada a igualdade das categorias de adesão duas a duas, medida pelo teste de Tukey não paramétrico. Não foram encontradas diferenças significativas em nenhum dos três grupos (vide Anexo II).

Tabela 5: Comparação das variáveis categóricas com o CEAT ( 3 categorias) pelo teste de Fisher.

\begin{tabular}{|c|c|c|c|c|c|c|c|c|}
\hline \multirow{2}{*}{ Fator } & \multirow{2}{*}{ Categoria } & \multicolumn{2}{|c|}{ CEAT: aderente estrito $(n=21)$} & \multicolumn{2}{|c|}{ CEAT: boa adesão $(n=16)$} & \multicolumn{2}{|c|}{ CEAT: pouco aderente $(n=14)$} & \multirow{2}{*}{ p-valor } \\
\hline & & $\mathrm{n}$ & $\%$ & $\mathrm{n}$ & $\%$ & $\mathrm{n}$ & $\%$ & \\
\hline \multirow[t]{2}{*}{ Gênero } & $\mathrm{F}$ & 5 & 23,81 & 4 & 25 & 3 & 21,43 & 1 \\
\hline & M & 16 & 76,19 & 12 & 75 & 11 & 78,57 & \\
\hline \multirow[t]{2}{*}{$\begin{array}{l}\text { Mecanismo de } \\
\text { transmissão }\end{array}$} & sexual & 17 & 80,95 & 12 & 85,71 & 10 & 83,33 & 1 \\
\hline & vertical & 4 & 19,05 & 2 & 14,29 & 2 & 16,67 & \\
\hline \multirow[t]{2}{*}{ Carga viral } & Indetectável & 16 & 76,19 & 11 & 68,75 & 7 & 50 & 0,292 \\
\hline & Detectável & 5 & 23,81 & 5 & 31,25 & 7 & 50 & \\
\hline \multirow[t]{4}{*}{ Nível Educacional } & Fundamental completo & 0 & 0 & 0 & 0 & 1 & 7,14 & 0,754 \\
\hline & Ensino Médio & 7 & 33,33 & 3 & 18,75 & 3 & 21,43 & \\
\hline & Ensino Superior & 13 & 61,91 & 13 & 81,25 & 10 & 71,43 & \\
\hline & Pós-doutorado & 1 & 4,76 & 0 & 0 & 0 & 0 & \\
\hline
\end{tabular}

*Mecanismo de transmissão não considera os desconhecidos para a análise (aderente estrito $n=21$, boa adesão $n=14$ e pouco aderente $n=12$ )

Tabela 6: Comparação das variáveis quantitativas com a escala CEAT dicotômica.

\begin{tabular}{|c|c|c|c|c|c|c|c|c|}
\hline \multirow{2}{*}{ Variável } & \multicolumn{2}{|c|}{ CEAT: aderente estrito $(n=21)$} & \multicolumn{2}{|c|}{ CEAT: boa adesão $(n=16)$} & \multicolumn{2}{|c|}{ CEAT: pouco aderente $(n=14)$} & \multirow{2}{*}{ Teste } & \multirow{2}{*}{ p-valor } \\
\hline & Media (DP) & Mediana (mín-max) & Media (DP) & Mediana (mín-max) & Media (DP) & Mediana (mín-max) & & \\
\hline Idade & $25,81(4,25)$ & $26(18-32)$ & $24,25(4,09)$ & $23,5(18-32)$ & $26,57(3,27)$ & $27(21-31)$ & Kruskal-Wallis & 0,259 \\
\hline Tempo de Infecção (anos) & $6,88(7,48)$ & $3(0,16-24)$ & $5,96(6,97)$ & $3,5(0,66-26)$ & $8,8(8,19)$ & $6,5(0,16-26)$ & Kruskal-Wallis & 0,534 \\
\hline
\end{tabular}




\subsection{Análise de Regressão Logística}

Foram realizados dois modelos de regressão logística neste estudo. O primeiro modelo foi o resultado da seleção entre as variáveis carga viral e todas as subescalas da BFP. Nenhuma escala permanece no modelo final após a seleção das variáveis.

O segundo modelo de regressão foi composto pelas variáveis carga viral e as escalas principais da BFP. O modelo final é composto apenas pelo fator Realização (Tabela 17), indicando este fator como preditor independente para adesão ao tratamento.

Na Figura 1, podemos verificar que os pontos não excedem as bandas de confiança, portanto não existem indícios de que os dados estejam mal ajustados.

Tabela 7: Resultado da regressão logística com as escalas principais da BFP.

\begin{tabular}{ccccccc}
\hline & Estimativa & Erro Padrão & Odds_Ratio & Lim_Inf & Lim_Sup & p-valor \\
\hline (Intercept) & -3.3242 & 2.2323 & 0.036001308 & 0.0004 & 2.8606 & 0.1364 \\
REALIZAÇÃO & 0.8582 & 0.4479 & 2.35891083 & 0.9805 & 5.6749 & $\mathbf{0 . 0 5 5 4}$ \\
\hline
\end{tabular}

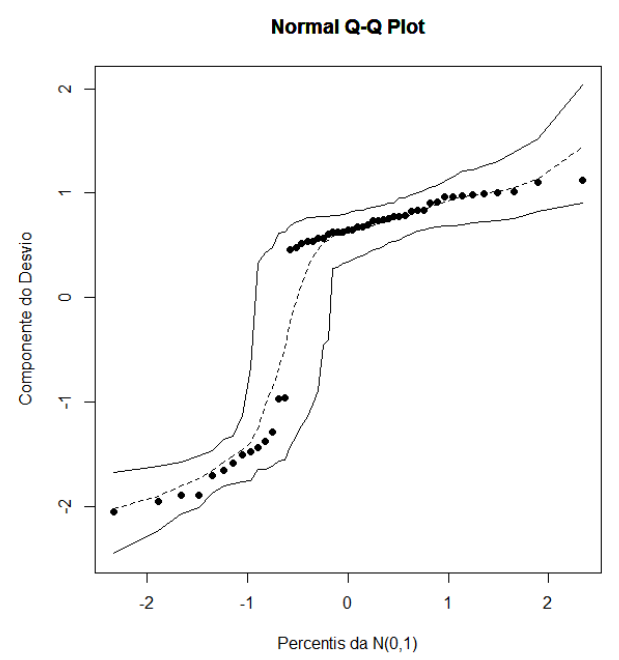

Figura 1: Gráfico de qualidade de ajuste da Regressão da Tabela 17. 
Ao ajustar o modelo da Tabela 17 notou-se que o coeficiente da regressão é muito sensível aos escores de Realização no grupo de pacientes pouco aderentes. Por exemplo, existem quatro pacientes $(6,7,14$ e 49) que são pouco aderentes e possuem escores de realização acima ou igual à 5,66. Estes pacientes, quando retirados da análise de regressão, deixam o escore de Realização mais significativo. Para contornar este problema apenas o paciente 14 foi retirado, pois possuía o maior escore de Realização entre os pacientes pouco aderentes (Tabela 18).

Tabela 8: Resultado da regressão logística com as escalas principais da BFP, sem o paciente 14.

\begin{tabular}{ccccccc}
\hline & Estimativa & Erro Padrão & Odds_Ratio & Lim_Inf & Lim_Sup & $p$-valor \\
\hline (Intercept) & -2.3204 & 2.4235 & 0.0982 & 0.0001 & 1.5367 & 0.0746 \\
REALIZAÇÃO & 1.0818 & 0.4925 & 2.95 & 1.1235 & 7.7456 & $\mathbf{0 . 0 2 8 1}$ \\
\hline
\end{tabular}

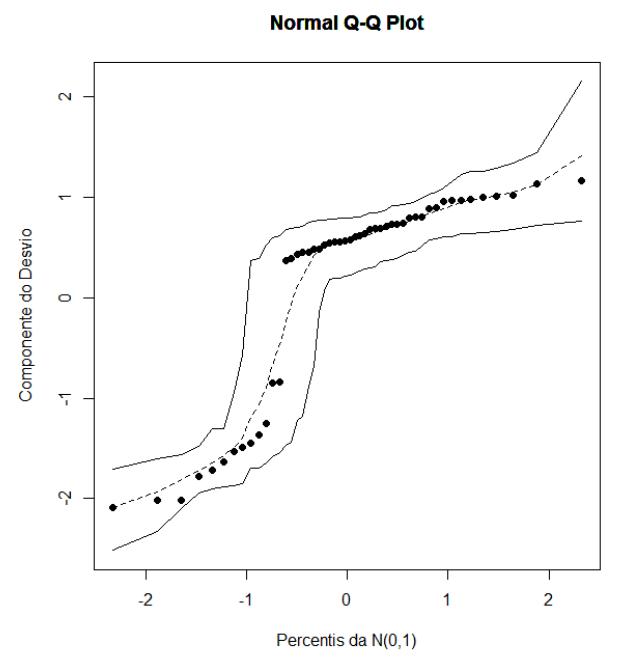

Figura 2: Gráfico de qualidade de ajuste da Regressão da Tabela 18. 


\section{DISCUSSÃO}

Apesar das diversas abordagens para identificar fatores de risco para a baixa adesão em pacientes portadores do HIV, poucos estudos têm avaliado especificamente a influência das características de personalidade na adesão ao tratamento antirretroviral (20). Alguns autores realizaram pesquisas com foco em características sóciodemográficas, qualidade de vida e transtornos psiquiátricos (5) (10) (31) (32), porém faz-se necessária a ampliação do olhar sobre os aspectos subjetivos que podem também contribuir para uma melhor a adesão por parte dos pacientes jovens.

\subsection{Divisão dos Grupos segundo grau de adesão:}

Os testes de associação e regressão foram realizados dividindo os pacientes de dois modos diferentes. No primeiro modelo foram agrupados os pacientes que apresentavam boa adesão e adesão estrita. Já no segundo modelo os pacientes foram divididos em três grupos: baixa adesão, boa adesão e adesão estrita. Quando os pacientes eram divididos em três grupos o número de pacientes em cada grupo fícava pequeno, prejudicando a análise estatística.

Quatro pacientes apresentavam mecanismos de transmissão "indefinido" e optou-se por não considerar esta variável na análise univariada, visto que o número muito baixo não seria suficiente para realizar comparações entre os grupos.

\subsection{Variáveis sócio-demográficas e Adesão ao tratamento:}

Não foi possível verificar associação entre as variáveis descritivas avaliadas e adesão ao tratamento nos pacientes jovens da amostra. $\mathrm{Na}$ literatura alguns fatores podem ser correlacionados a baixa adesão ao tratamento antirretroviral como, por exemplo, ser do gênero feminino, possuir baixa escolaridade, ter menos de 40 anos, ausência de suporte social/afetivo ou percepção deste suporte como insuficiente, relação insatisfatória do usuário com a equipe de saúde, informações inadequadas a respeito da doença, uso de drogas ilícitas, dentro outras. Os fatores associados a adesão adequada são compreensão correta sobre a doença e tratamento, bom vínculo com a equipe de saúde, participação da equipe multidisciplinar no tratamento, apoio social e afetivo de 
qualidade, bem como a capacidade para reconhecer e aceitar este apoio (5) (6) (9) (7) (32) (31).

Não foram encontradas diferenças estatísticas significantes entre adesão de homens ou mulheres ou relacionada a diferentes níveis educacionais, o que difere dos resultados encontrados na literatura (31) (32). Tal fato poderia ser explicado pelo alto grau de aderência dos pacientes da amostra a TARV e também pelo alto nível educacional da amostra. A adesão desta coorte vem sendo avaliada pelos profissionais da equipe de saúde e, atualmente, pode-se afirmar que em torno de $70 \%$ dos pacientes aderem de modo estrito ou adequado, indicando uma taxa de sucesso terapêutico em torno de $90 \%(33)$.

A equipe multidisciplinar é formada por médicos, psicólogos, nutricionistas, farmacêuticos e todos os pacientes recebem o suporte completo e adequado desde a primeira consulta. Estes pacientes são tratados de modo integral, não apenas com o foco na melhora de seu quadro clínico. Sendo assim, este estudo evidencia a possibilidade de que a alta complexidade da equipe de saúde possa contribuir para uma melhor qualidade no atendimento, proporcionando condições para adesão adequada na coorte como um todo (5) (33).

\subsection{Fatores de Personalidade e Adesão}

$\mathrm{Na}$ análise univariada, que dividiu os pacientes em dois grupos de acordo com o grau de adesão (adesão boa/estrita e baixa adesão), foi possível verificar tendências de associação entre o fator Realização e suas facetas Ponderação e Empenho com adesão ao tratamento. Quando a análise é realizada dividindo os pacientes em três grupos esta tendência desaparece, o que pode ser explicado pelo baixo número de pacientes em cada um dos grupos.

Em relação as análises multivariadas, na primeira regressão logística foram incluídas as variáveis carga viral e subescalas da BFP e, nesta análise, nenhum fator apareceu relacionado a adesão. Na segunda análise de regressão, foram incluídas as variáveis carga viral e escalas principais da BFP e o fator Realização surge como preditor independente para adesão ao tratamento antirretroviral.

$\mathrm{Na}$ literatura, o dado carga viral aparece relacionado a adesão ao tratamento visto que o paciente que possui adesão adequada tende a manter sua carga viral 
indetectável por maior tempo (5) (6) (10) (31).

Em ambas as regressões o item carga viral foi incluído por aparentar ser fator de confusão, visto que alguns pacientes aderentes ainda possuíam carga viral detectável e outros não aderentes já estavam indetectáveis. Tal fato pode ser explicado pela possibilidade de que os participantes do estudo não possuíam exatamente o mesmo tempo de início de tratamento. Sendo assim, aqueles que iniciaram a TARV recentemente, mesmo demonstrando aderência, ainda poderiam apresentar carga viral detectável. Também é necessário salientar que a resposta imunológica é muito particular de cada indivíduo e pode ser possível que alguns pacientes ainda apresentassem carga viral indetectável, mesmo demonstrando falhas no tratamento.

Faz-se necessário levar em consideração o fato de que o questionário CEAT não avalia somente tópicos relacionados ao uso de medicação. Por ser bastante completo, também avalia a relação do paciente com a equipe de saúde, sua auto-percepção a respeito das condições de levar o tratamento adiante, o quanto de informação possui sobre a medicação e se realmente acredita que ela lhe possa trazer algum benefício. Deste modo, se um paciente responde de modo positivo para todos os itens relacionados à ingestão de medicação (toma a medicação regularmente), porém demonstra possuir uma relação ruim com a equipe de saúde e auto-percepção negativa, o escore de seu questionário será mais baixo, indicando baixa adesão (paciente em risco para baixa adesão).

Alguns estudos apontam o fator Realização como preditor independente para boa adesão ao tratamento em diferentes enfermidades (21) (22). O item Realização diz respeito ao grau de organização, persistência, controle e motivação do indivíduo para atingir metas, cumprir e alcançar objetivos. Pessoas com altos escores neste fator tendem a ser confiáveis, pontuais, decididas, organizadas e perseverantes. Já as pessoas com baixo escore tendem a ser menos rígidas e disciplinadas, com objetivos menos claros, negligentes e mais descuidadas (19).

Sabe-se que o sucesso de um tratamento em saúde não se restringe apenas a compreensão e seguimento das orientações médicas, mas também diz respeito à capacidade do indivíduo em sentir-se preparado para este seguimento e ao comprometimento com sua saúde. O paciente que não possui adequada capacidade de organização, disciplina, clareza em relação aos objetivos do tratamento e reconhecimento de que isto é algo positivo e necessário para sua vida tende a ser menos 
aderente (34). Deste modo, as características de personalidade relacionadas ao fator Realização podem influenciar a baixa adesão ao tratamento, mesmo quando todos os outros aspectos apontados pela literatura (frequentemente mais avaliados nas consultas) aparentam estar adequados (5) (6) (32).

Um fato interessante encontrado neste estudo diz respeito ao fator Neuroticismo que, nesta amostra, não possui correlação com baixa adesão ao tratamento. Por ser um fator que faz referência a fragilidade e instabilidade emocional, sentimentos depressivos, dificuldades em lidar com críticas, insegurança e tendência ao pessimismo e passividade, ele foi associado à baixa adesão em algumas pesquisas já realizadas (21) (22).

Diversos estudos na literatura apontam a depressão como um dos principais diagnósticos psiquiátricos concomitantes a infecção pelo vírus HIV, exercendo forte influência na adesão ao tratamento dos pacientes. (35) (36) (37). As taxas de prevalência de depressão variam de $12 \%$ a $66 \%$ e o transtorno não é diagnosticado em aproximadamente $50 \%$ dos pacientes infectados (38). O paciente portador do vírus geralmente passa por períodos em que seu estado emocional encontra-se abalado. A confirmação do diagnóstico traz diversas questões ligadas a insegurança em relação a sua saúde e seus vínculos sociais e afetivos, medo do preconceito, mudança de estilo de vida, visitas mais frequentes ao hospital ou centro de saúde, tomada de medicação diária, dentre outros. No caso deste trabalho, a grande maioria dos pacientes que fazem parte do ambulatório ADEE 3002 são encaminhados do Hemocentro de São Paulo, localizado no Hospital das Clínicas. São indivíduos que voluntariamente se propuseram a doar sangue e necessitaram lidar com a confirmação de um diagnóstico inesperado, que causou grande impacto em suas vidas. Todos estes aspectos contribuem para o aumento da fragilidade e instabilidade emocional que, quando não avaliadas, podem levar o paciente a desenvolver um quadro de depressão, muitas vezes com consequências graves.

Analisando os resultados encontrados, pode-se levantar a hipótese de que o fator Realização esteja agindo como protetor ao alto escore em Neuroticismo, "neutralizando" os efeitos negativos decorrentes deste, permitindo que o paciente continuasse seu tratamento de modo eficiente. É possível pensar que pacientes com sintomas depressivos podem-se manter aderentes ao tratamento quando outras características de personalidade são modificadas e fortificadas, indicando boas 
perspectivas em adesão neste tipo de quadro psiquiátrico.

Outra hipótese a ser levantada é de que este serviço de saúde oferece aos pacientes um atendimento integrado e de qualidade. Todos aqueles que demonstram possuir sintomas de depressão e instabilidade emocional logo são avaliados e encaminhados para psicologia e/ou psiquiatria. Os efeitos negativos deste estado emocional podem ser minimizados, visto que ação terapêutica individual ou em grupo acontece rapidamente, não permitindo que o quadro depressivo se prolongue.

O grande diferencial deste estudo é chamar a atenção para algumas características específicas de personalidade que estão relacionadas à adesão e que devem ser levadas em consideração no atendimento ao paciente jovem portador do HIV. Visto que o número de indivíduos infectados tem aumentado, principalmente na faixa dos 18 a 24 anos (2) (3), é de extrema importância o desenvolvimento de estudos que avaliem quais fatores específicos estejam relacionados ao sucesso terapêutico e quais aspectos de personalidade destes jovens são facilitadores ou empecilhos ao seguimento correto do tratamento.

Os aspectos que geralmente recebem maior atenção dos profissionais da saúde durante os atendimentos são a existência ou não de transtorno psiquiátrico, aceitação do diagnóstico e a existência e qualidade dos vínculos sociais e afetivos para suporte emocional.

As características individuais de personalidade também exercem grande influência sobre o comportamento em saúde dos indivíduos e talvez sejam a chave para uma compreensão mais integrada e completa dos processos psíquicos associados a condutas adequadas no tratamento do HIV. Aspectos relacionados a capacidade psíquica do indivíduo em seguir o tratamento, o grau de motivação e autoconfiança, nível de organização pessoal, clareza de ideias e disponibilidade para atingir seus próprios objetivos, evidenciados neste estudo, raramente são avaliados.

Como os resultados apresentados demonstram que estes aspectos estejam fortemente correlacionados a adesão ao tratamento, faz-se necessária uma mudança de postura da equipe em relação ao paciente, ampliando o olhar para questões que não são frequentemente avaliadas. Deste modo, seria possível conseguir identificar as falhas terapêuticas de modo mais específico

Este estudo também enfatiza a importância do papel do psicólogo na equipe de saúde, bem como do acompanhamento psicológico frequente para os pacientes. As 
características de personalidade são passíveis de ajustamento e modificação no trabalho de psicoterapia e torna-se fundamental que todas as equipes de saúde possuam este profissional como parte do grupo. Somente este profissional pode avaliar efetivamente quais fatores psicológicos estariam influenciando a baixa adesão e criar condições para que a equipe de saúde desenvolva estratégias específicas e realmente eficazes.

Sendo assim, é possível contribuir para uma maior integração entre os profissionais de saúde e oferecer ao paciente a oportunidade de desenvolver condições psicológicas a continuidade de seu tratamento de modo adequado. Também é possível melhorar a qualidade de vida destes indivíduos e, consequentemente, contribuir para a diminuição dos índices de transmissão do HIV na população geral, principalmente nos grupos de maior vulnerabilidade, como os jovens. 


\section{CONCLUSÕES}

Este trabalhado teve como objetivo avaliar a relação entre características de personalidade e adesão ao tratamento em pacientes jovens portadores do HIV.

A prevalência de adesão destes pacientes foi bastante elevada, em torno de $70 \%$, e a análise dos dados sugere que o fator de personalidade correlacionado a adesão ao tratamento antirretroviral é Realização. Este fator também é preditor independente para adesão. Tais resultados reforçam a necessidade de inclusão destes aspectos na avaliação integral realizada pela equipe de saúde ao paciente jovem portador do HIV, principal grupo vulnerável atualmente.

Os dados também reforçam a importância do profissional da área da psicologia como parte da equipe, realizando um trabalho de ajuste e modificação das características de personalidade que influenciam a adesão. Oferecer ao paciente a oportunidade de melhorar as condições psicológicas necessárias para seguir com o tratamento faz parte do desenvolvimento de estratégias de atendimento mais específicas e eficazes. 


\section{LIMITAÇÕES DO ESTUDO E PERSPECTIVAS:}

O estudo apresenta algumas limitações como, por exemplo, não ter alcançado o número de 60 pacientes determinado pelo cálculo amostral. A amostra avaliada de 51 pacientes representa $85 \%$ do total estabelecido e pode-se pensar que o aumento do número de pacientes reforce os resultados encontrados e até mostre novas associações ainda não avaliadas. Vale ressaltar que a coorte de pacientes do ambulatório ADEE 3002 é composta por pacientes mais velhos e as consultas acontecem apenas uma vez por semana, o que acabou por dificultar a participação de pacientes mais jovens, tornando o período de coleta mais longo (um ano e meio).

Também é necessário levar em consideração que a coorte do ambulatório ADEE 3002 é composta por pacientes encaminhados pelo Hemocentro de São Paulo, localizado no Hospital das Clínicas. O grau de adesão ao tratamento neste ambulatório, no geral, é bastante alto e os indivíduos avaliados possuem um alto nível de escolaridade. Tais características tornam esta amostra bastante específica e diferenciada.

No intuito de ampliar os resultados encontrados, o estudo continuará a ser realizado como pesquisa de doutorado e os dados serão coletados em outro centro de tratamento a pacientes portadores do HIV; possibilitando a comparação de populações com perfis diferentes. 


\section{REFERÊNCIAS BIBLIOGRÁFICAS}

1. UNAIDS. [Online].; 2011 [cited 2016 January 11. Available from: http://www.unaids.org.

2. Ministério da Saúde. Boletim Epidemiológico HIV/AIDS. [Online].; 2014 [cited 2015 Julho 15. Available from: http://www.aids.gov.br/sites/default/files/anexos/publicacao/2014/56677/b oletim_2014_final_pdf_15565.pdf.

3. Ministério da Saúde. Boletim Epidemiológico AIDS/DST 2011. [Online].; 2011 [cited 2015 Julho 15. Available from:

http://www.aids.gov.br/sites/default/files/anexos/publicacao/2011/50652/b oletim_aids_2011_final_m_pdf_26659.pdf.

4. The INSIGHT START Study Group. Initiation of Antiretroviral Therapy in Early Asymptomatic HIV Infection. The New England Journal of Medicine. 2015 August 27; 373: p. 795-807.

5. Polejack L, Seidl EMF. Monitoramento e avaliação da adesão ao tratamento antirretroviral para HIV/aids: desafios e possibilidades. Ciência e Saúde Cletiva. 2010; 15(1): p. 1201-1208.

6. Ministério da Saúde. Secretaria de Vigilância em Saúde. Programa Nacional de DST e Aids. Manual de adesão ao tratamento para pessoas vivendo com HIV e aids. [Online].; 2008 [cited 2015 Julho 15. Available from: http://www.aids.gov.br/sites/default/files/Manual_de_adesao_web.pdf.

7. Remor E, Milner-Moskovics J, Preussler G. Adaptação Brasileira do "Cuestionário para la Evaluación de la Adhesión al Tratamiento Antiretroviral. Revista de Saúde Pública. 2007 Outubro; 41(5): p. 685-694.

8. Remor E. Systematic Review of the Psychometric Properties of the Questionnaire to Evaluate the Adherence to HIV Therapy (CEAT-VIH). Patient. 2012; 6: p. 61-73.

9. Mills EJ, Nachega JB, Bangsberg DR, Singh S, Rachlis B, Wu P, et al. Adherence to HAART: A Systematic Review of Developed and Developing Nation PatientReported Barriers and Facilitators. PLOS Medicine. 2006 November 21; 3(11).

10 Resende RC, Podestá MHMC, Souza W, Barroso TdO, Boas OMGdCV, Ferreira EB. . Adesão ao tratamento antirretroviral de pacientes vivendo com HIV/AIDS atendidos pelo Sistema Único de Saúde. Rev. Universidade Vale do Rio Verde. 2012 Dezembro; 10(2): p. 186-201.

11 Organization WH. World Health Organization. [Online]. [cited 20151203. . Available from: http://www.who.int/en/.

12 González RF. Personalidade, Saúde e Modo de Vida. Psicologia Teoria e Prática. . 2004.

13 Thomas CV, Castro EK. Personalidade, Comportamentos de saúde e adesão ao . tratamento a partir do modelo dos cinco grandes fatores: Uma revisão de literatura. Psicologia, Saúde e Doenças. 2012; 13(1): p. 100-109.

14 Nunes CHSdS, Hutz CS, Nunes MFO. Manual Técnico da Baterial Fatorial de . Personalidade Ltda CLeE, editor. Itatiba; 2010. 
15 Natividade JC, Aguirre AR, Bizarro L, Hutz CS. Fatores de personalidade como - preditores do consumo de álcool por estudantes universitários. Caderno de Saúde Pública. 2012; 28(6): p. 1091-1100.

16 Robert R. McCrae OPJ. An Introduction to the Five-Factor Model and Its . Applications. Journal of Personality. 1992 Junho; 60(2): p. 175-215.

17 Feist J, Feist GJ, Roberts TA. Teorias da Personalidade Artmed , editor. Porto . Alegre; 2015.

18 Lawrence A. Pervin OPJ. Personalidade: teoria e pesquisa Artmed, editor.; 2008.

19 Nunes CHSdS, Hutz C. Bateria Fatorial de Personalidade: Manual Técnico . Psicólogo Cd, editor. São Paulo; 2010.

20 Souza JAd. Repositório Institucional. [Online].; 2007 [cited 2015 Outubro 1. . Available from: http://repositorio.unb.br/handle/10482/2279.

21 Axelsson M, Brink E, Lundgren J, Lotvall J. The Influence of Personality Traits on . Reported Adherence to Medication in Individuals with Chronic Disease: An Epidemiological Study in West Sweden. Plus One. 2011 Março 28; 6(3).

22 Axelsson M, Emilsson M, Brink E, Torén K, Lundgreen J, Lotvall J. Personality, . adherence, asthma control and health-related quality of life in young adult asthmatics. Respiratory Medicine. 2009 Julho; 103(7): p. 1033-1040.

23 Dobbels F, Vanhaecke J, Dupont L, Nevens F, Verleden G, Pirenne J, et al. . Pretransplant predictors of posttransplant adherence and clinical outcome: an evidence base for pretransplant psychosocial screening. Transplantation. 2009; 87(10): p. 1497-1504.

24 Jerant A, Chapman BP, Duberstein P. Personality and medication non-adherence . among older adults enrolled in a six-year trial. British Journal of health Psychology. 2011; 16(1): p. 151-169.

25 UNAIDS. UNAIDS. [Online].; 2011 [cited 2016 January 16. Available from: . www.unaids.org.

26 Anderson W, Darling DA. A Test of Goodness-of-Fit. Journal of the American . Statistical Association. 1954; 49: p. 765-769.

27 Siegel S, Castellan NJ. Nonparametric Statistics. 2nd ed. New York: McGraw-Hill; 1988.

28 Jr DWH, Lemeshow S. Applied logistic regression Sons. JW\&, editor.; 2004.

29 Henrique IAS, Micheli D, Lacerda RB. Validação da versão brasileira do teste de . triagem do envolvimento com álcool, cigarro e outras substâncias (ASSIST). Revista Associação Médica Brasileira. 2004; 50(2): p. 199-206.

30 Association AP. Diagnostic and statistical manual of mental disorders: DSM-IV . Washington; 1994.

31 Silveira MPT, Maurer P, Gutier MC, Moreira LB. Factors associated with . therapeutic sucess in HIV-positive individuals in southern Brazil. Journal of Clinical Pharmacy and Therapeutics. 2015; 40: p. 192-195.

32 Bonolo PF, Ceccato MGB, Rocha GM, Arcurio FA, Campos LN, Guimarares MDC. . Gender differences in non-adherence among brazilian patients initiating 
antiretroviral therapy. Clinics. 2014; 68(5): p. 612-650.

33 Sabino TE, Fonseca LAM, Casseb JSRJ. Uso do CEATH para avaliar adesão ao . tratamento antirretroviral de pessoas vivendo com HIV/aids: associação da carga viral com o grau de adesão. Resumo. Núcleo de Apoio a Pesquisa em Retrovírus, Departamento de Dermatologia, HCFMUSP.

34 Kim SH, McDonald S, Kim S, Foster C, Sarah Fidler. Importance of Self-Motivation . and Social Support in Medication Adherence in HIV-Infected Adolescents in the United Kingdom and Ireland: A Multicentre HYPNet Study. AIDS Patient Care and STDs. 2015; 29(6).

35 Silva FS, Oliveira FBM, Mendes CC, Silva G, Santos SOd, Pessoa RMC. Preditores . associados á qualidade de vida em pessoas vivendo com hiv/aids: revisão integrativa. Revista Prevenção de Infecção e Saúde. 2015; 1(2).

36 Silva JB, Cardoso GCP, Netto AR, Kritski AL. Os significados da comorbidade para . os pacientes vivendo com TB/HIV: repercussões no tratamento. Physis: Revista de Saúde Coletiva. 2015; 25(1).

37 Poletto MP, Heck C, Calsa DdC, Moskovics JM. Pensamentos automáticos e . crenças centrais associados ao HIV/AIDS em indivíduos soropositivos. Temas em Psicologia. 2015 Junho; 22(2).

38 Silveira MPT, Guttier MC, Pinheiro CAT, Pereira TVS, Cruzeiro ALS, Moreira LB.

. Depressive symptoms in HIV-infected patients treated with highly active antiretroviral therapy. Revista Brasileira de Psiquiatria. 2015; 34(2): p. 162-167.

39 W. O. Bussab PM. Estatística Básica. 7th ed. São Paulo: Saraiva; 2011.

40 Feist J, Feist GJ, Roberts TA. Teorias da Personalidade Artmed, editor. Porto . Alegre; 2015. 


\section{ANEXO I}

Tabela 9: Comparação da escala e subescalas de Neuroticismo com o CEAT (2 categorias)

\begin{tabular}{|c|c|c|c|c|c|c|}
\hline \multirow{2}{*}{ Variável } & \multicolumn{2}{|c|}{ CEAT: boa adesão $(n=37)$} & \multicolumn{2}{|c|}{ CEAT: pouco aderente $(n=14)$} & \multirow{2}{*}{ Teste } & \multirow{2}{*}{$\mathrm{p}$-valor } \\
\hline & Media (DP) & Mediana (mín-max) & Media (DP) & Mediana (mín-max) & & \\
\hline Neuroticismo & $3,71(1,11)$ & $3,74(1,64-5,7)$ & $3,51(1)$ & $3,77(1,83-4,81)$ & $\mathrm{t}$ & 0,554 \\
\hline Vulnerabilidade & $3,91(1,36)$ & $4(1,67-6,33)$ & $3,36(1,47)$ & $3,62(1,11-5,78)$ & $\mathrm{t}$ & 0,236 \\
\hline Instabilidade & $4,35(1,47)$ & $4,5(1,67-7)$ & $3,99(0,91)$ & $4,25(2,33-5,33)$ & $\mathrm{t}$ & 0,299 \\
\hline Passividade & $3,84(1,3)$ & $4(1,17-6)$ & $4,02(1,78)$ & $3,75(1-6,67)$ & $\mathrm{t}$ & 0,724 \\
\hline Depressão & $2,8(1,35)$ & $2,5(1-6,38)$ & $2,68(1,15)$ & $2,44(1-4,75)$ & $t$ & 0,763 \\
\hline
\end{tabular}

Tabela 10: Comparação da escala e subescalas de Extroversão com o CEAT (2 categorias)

\begin{tabular}{|c|c|c|c|c|c|c|}
\hline \multirow{2}{*}{ Variável } & \multicolumn{2}{|c|}{ CEAT: boa adesão ( $n=37)$} & \multicolumn{2}{|c|}{ CEAT: pouco aderente $(n=14)$} & \multirow{2}{*}{ Teste } & \multirow{2}{*}{ p-valor } \\
\hline & Media (DP) & Mediana (mín-max) & Media (DP) & Mediana (mín-max) & & \\
\hline Extroversão & $4,65(1,07)$ & $4,52(2,35-6,66)$ & $4,79(0,67)$ & $4,99(3,04-5,7)$ & $\mathrm{t}$ & 0,581 \\
\hline Nível de comunicação & $4,29(1,4)$ & $4,33(1,5-6,83)$ & $4,28(1,05)$ & $4,33(1,33-5,83)$ & $\mathrm{t}$ & 0,992 \\
\hline Altivez & $4,18(1,22)$ & $4,14(1,86-6,71)$ & $4,32(1,02)$ & $4,36(2,57-6,14)$ & $\mathrm{t}$ & 0,692 \\
\hline Dinamismo & $4,98(1,26)$ & $4,8(3-7)$ & $5,16(1,01)$ & $5(3,4-7)$ & Mann-Whitney & 0,597 \\
\hline Interações Sociais & $5,14(1,22)$ & $5,43(2,29-7)$ & $5,4(0,93)$ & $5,29(4-7)$ & $t$ & 0,418 \\
\hline
\end{tabular}

Tabela 11: Comparação da escala e subescalas de Socialização com o CEAT (2 categorias)

\begin{tabular}{|c|c|c|c|c|c|c|}
\hline \multirow{2}{*}{ Variável } & \multicolumn{2}{|c|}{ CEAT: boa adesão ( $n=37)$} & \multicolumn{2}{|c|}{ CEAT: pouco aderente $(n=14)$} & \multirow{2}{*}{ Teste } & \multirow{2}{*}{ p-valor } \\
\hline & Media (DP) & Mediana (mín-max) & Media (DP) & Mediana (mín-max) & & \\
\hline Socialização & $5,18(0,59)$ & $5,25(3,88-6,31)$ & $5,14(0,9)$ & $5,33(2,89-6,86)$ & Mann-Whitney & 0,825 \\
\hline Amabilidade & $5,94(0,65)$ & $6,08(4-6,92)$ & $5,79(0,66)$ & $5,75(4,42-6,75)$ & Mann-Whitney & 0,245 \\
\hline Pró-sociabilidade & $5,37(1,06)$ & $5,5(2,5-7)$ & $5,2(1,19)$ & $5,38(3-7)$ & $\mathrm{t}$ & 0,633 \\
\hline Confiança & $4,23(1)$ & $4,25(1,38-6,13)$ & $4,43(1,31)$ & $4,63(1,25-7)$ & $\mathrm{t}$ & 0,612 \\
\hline
\end{tabular}

Tabela 12: Comparação da escala e subescalas de Realização com o CEAT (2 categorias)

\begin{tabular}{|c|c|c|c|c|c|c|}
\hline \multirow{2}{*}{ Variável } & \multicolumn{2}{|c|}{ CEAT: boa adesão $(n=37)$} & \multicolumn{2}{|c|}{ CEAT: pouco aderente $(n=14)$} & \multirow{2}{*}{ Teste } & \multirow{2}{*}{$\mathrm{p}$-valor } \\
\hline & Media (DP) & Mediana (mín-max) & Media (DP) & Mediana (mín-max) & & \\
\hline Realização & $5,24(0,65)$ & $5,24(4,11-6,51)$ & $4,75(0,96)$ & $4,8(2,96-6,05)$ & $\mathrm{t}$ & 0,098 \\
\hline Competência & $5,4(0,9)$ & $5,4(3,6-7)$ & $5,29(1,12)$ & $5,1(3,9-7)$ & $\mathrm{t}$ & 0,746 \\
\hline Ponderação & $4,95(1,38)$ & $5(1-7)$ & $4,18(1,55)$ & $4,12(1-7)$ & Mann-Whitney & 0,081 \\
\hline Empenho & $5,36(0,83)$ & $5,14(3,57-7)$ & $4,78(1,12)$ & $4,71(2,86-6,57)$ & $t$ & 0,1 \\
\hline
\end{tabular}


Tabela 13: Comparação da escala e subescalas de Abertura com o CEAT (2 categorias)

\begin{tabular}{|c|c|c|c|c|c|c|}
\hline \multirow{2}{*}{ Variável } & \multicolumn{2}{|c|}{ CEAT: boa adesão ( $n=37)$} & \multicolumn{2}{|c|}{ CEAT: pouco aderente $(n=14)$} & \multirow{2}{*}{ Teste } & \multirow{2}{*}{ p-valor } \\
\hline & Media (DP) & Mediana (mín-max) & Media (DP) & Mediana (mín-max) & & \\
\hline Abertura & $5,12(0,67)$ & $5,11(3,99-6,69)$ & $4,75(1,06)$ & $4,6(3,06-6,42)$ & $t$ & 0,249 \\
\hline Abertura a ideias & $5,18(0,96)$ & $5,2(2,4-6,7)$ & $4,84(1,14)$ & $4,5(2,6-6,7)$ & $\mathrm{t}$ & 0,343 \\
\hline Liberalismo & $5,37(0,91)$ & $5,43(3,29-7)$ & $5,16(1,01)$ & $5,08(3,57-7)$ & $\mathrm{t}$ & 0,491 \\
\hline Busca por novidades & $4,81(0,94)$ & $4,83(2,5-6,67)$ & $4,39(1,21)$ & $4(3-6,67)$ & $\mathrm{t}$ & 0,254 \\
\hline
\end{tabular}




\section{ANEXO II}

Tabela 14: Comparação da escala e subescalas de Neuroticismo com a escala CEAT padrão.

\begin{tabular}{|c|c|c|c|c|c|c|c|c|}
\hline \multirow{2}{*}{ Variável } & \multicolumn{2}{|c|}{ CEAT: aderente estrito $(n=21)$} & \multicolumn{2}{|c|}{ CEAT: boa adesão $(n=16)$} & \multicolumn{2}{|c|}{ CEAT: pouco aderente $(n=14)$} & \multirow{2}{*}{ Teste } & \multirow{2}{*}{$\mathrm{p}$-valor } \\
\hline & Media (DP) & Mediana (mín-max) & Media (DP) & Mediana (mín-max) & Media (DP) & Mediana (mín-max) & & \\
\hline Neuroticismo & $3,57(1,15)$ & $3,71(1,97-5,33)$ & $3,88(1,07)$ & $3,9(1,64-5,7)$ & $3,51(1)$ & $3,77(1,83-4,81)$ & Kruskal-Wallis & 0,626 \\
\hline Vulnerabilidade & $3,82(1,37)$ & $3,67(1,78-6,33)$ & $4,03(1,38)$ & $4(1,67-6,33)$ & $3,36(1,47)$ & $3,62(1,11-5,78)$ & Kruskal-Wallis & 0,395 \\
\hline Instabilidade & $4,21(1,56)$ & $4,5(1,67-7)$ & $4,53(1,36)$ & $4,5(1,83-6,83)$ & $3,99(0,91)$ & $4,25(2,33-5,33)$ & Kruskal-Wallis & 0,47 \\
\hline Passividade & $3,84(1,32)$ & $4(1,67-5,83)$ & $3,83(1,31)$ & $4,08(1,17-6)$ & $4,02(1,78)$ & $3,75(1-6,67)$ & Kruskal-Wallis & 0,932 \\
\hline Depressão & $2,54(1,27)$ & $2,25(1-5,13)$ & $3,14(1,42)$ & $3,13(1,38-6,38)$ & $2,68(1,15)$ & $2,44(1-4,75)$ & Kruskal-Wallis & 0,423 \\
\hline
\end{tabular}

Tabela 15: Comparação da escala e subescalas de Extroversão com a escala CEAT padrão.

\begin{tabular}{|c|c|c|c|c|c|c|c|c|}
\hline \multirow{2}{*}{ Variável } & \multicolumn{2}{|c|}{ CEAT: aderente estrito $(n=21)$} & \multicolumn{2}{|c|}{ CEAT: boa adesão $(n=16)$} & \multicolumn{2}{|c|}{ CEAT: pouco aderente $(n=14)$} & \multirow{2}{*}{ Teste } & \multirow{2}{*}{ p-valor } \\
\hline & Media (DP) & Mediana (mín-max) & Media (DP) & Mediana (mín-max) & Media (DP) & Mediana (mín-max) & & \\
\hline Extroversão & $4,51(1,11)$ & $4,52(2,35-6,66)$ & $4,83(1,02)$ & $4,83(3,27-6,63)$ & $4,79(0,67)$ & $4,99(3,04-5,7)$ & Kruskal-Wallis & 0,631 \\
\hline Nível de comunicação & $3,92(1,37)$ & $3,67(1,5-6,5)$ & $4,77(1,32)$ & $4,75(2,33-6,83)$ & $4,28(1,05)$ & $4,33(1,33-5,83)$ & Kruskal-Wallis & 0,186 \\
\hline Altivez & $4,13(1,29)$ & $4,43(1,86-6,14)$ & $4,24(1,15)$ & $4,07(2,29-6,71)$ & $4,32(1,02)$ & $4,36(2,57-6,14)$ & Kruskal-Wallis & 0,867 \\
\hline Dinamismo & $4,92(1,36)$ & $4,6(3-7)$ & $5,05(1,17)$ & $5(3,2-7)$ & $5,16(1,01)$ & $5(3,4-7)$ & Kruskal-Wallis & 0,797 \\
\hline Interações Sociais & $5,06(1,37)$ & $5,43(2,29-7)$ & $5,24(1,03)$ & $5,21(3,14-7)$ & $5,4(0,93)$ & $5,29(4-7)$ & Kruskal-Wallis & 0,853 \\
\hline
\end{tabular}

Tabela 16: Comparação da escala e subescalas de Socialização com a escala CEAT padrão.

\begin{tabular}{|c|c|c|c|c|c|c|c|c|}
\hline \multirow{2}{*}{ Variável } & \multicolumn{2}{|c|}{ CEAT: aderente estrito $(n=21)$} & \multicolumn{2}{|c|}{ CEAT: boa adesão $(n=16)$} & \multicolumn{2}{|c|}{ CEAT: pouco aderente $(n=14)$} & \multirow{2}{*}{ Teste } & \multirow{2}{*}{ p-valor } \\
\hline & Media (DP) & Mediana (mín-max) & Media (DP) & Mediana (mín-max) & Media (DP) & Mediana (mín-max) & & \\
\hline Socialização & $5,14(0,68)$ & $5,29(3,88-6,31)$ & $5,24(0,47)$ & $5,21(4,58-6,17)$ & $5,14(0,9)$ & $5,33(2,89-6,86)$ & Kruskal-Wallis & 0,908 \\
\hline Amabilidade & $5,82(0,78)$ & $6(4-6,92)$ & $6,1(0,4)$ & $6,08(5,5-6,75)$ & $5,79(0,66)$ & $5,75(4,42-6,75)$ & Kruskal-Wallis & 0,353 \\
\hline Pró-sociabilidade & $5,43(1,16)$ & $5,63(2,5-7)$ & $5,3(0,95)$ & $5,19(3,38-6,63)$ & $5,2(1,19)$ & $5,38(3-7)$ & Kruskal-Wallis & 0,741 \\
\hline Confiança & $4,17(1,11)$ & $4,25(1,38-5,88)$ & $4,31(0,85)$ & $4,25(2,63-6,13)$ & $4,43(1,31)$ & $4,63(1,25-7)$ & Kruskal-Wallis & 0,838 \\
\hline
\end{tabular}

Tabela 17: Comparação da escala e subescalas de Realização com a escala CEAT padrão.

\begin{tabular}{|c|c|c|c|c|c|c|c|c|}
\hline \multirow{2}{*}{ Variável } & \multicolumn{2}{|c|}{ CEAT: aderente estrito $(n=21)$} & \multicolumn{2}{|c|}{ CEAT: boa adesão $(n=16)$} & \multicolumn{2}{|c|}{ CEAT: pouco aderente $(n=14)$} & \multirow{2}{*}{ Teste } & \multirow{2}{*}{ p-valor } \\
\hline & Media (DP) & Mediana (mín-max) & Media (DP) & Mediana (mín-max) & Media (DP) & Mediana (mín-max) & & \\
\hline Realização & $5,21(0,68)$ & $5,24(4,11-6,51)$ & $5,28(0,63)$ & $5,18(4,17-6,39)$ & $4,75(0,96)$ & $4,8(2,96-6,05)$ & Kruskal-Wallis & 0,289 \\
\hline Competência & $5,4(1,05)$ & $5,5(3,6-7)$ & $5,4(0,69)$ & $5,3(4,3-6,4)$ & $5,29(1,12)$ & $5,1(3,9-7)$ & Kruskal-Wallis & 0,917 \\
\hline Ponderação & $4,88(1,5)$ & $5(1-7)$ & $5,03(1,24)$ & $5,38(2,75-6,75)$ & $4,18(1,55)$ & $4,12(1-7)$ & Kruskal-Wallis & 0,212 \\
\hline Empenho & $5,32(0,78)$ & $5,43(3,86-6,71)$ & $5,4(0,92)$ & $5,14(3,57-7)$ & $4,78(1,12)$ & $4,71(2,86-6,57)$ & Kruskal-Wallis & 0,229 \\
\hline
\end{tabular}


Tabela 18: Comparação da escala e subescalas de Abertura com a escala CEAT padrão.

\begin{tabular}{|c|c|c|c|c|c|c|c|c|}
\hline \multirow{2}{*}{ Variável } & \multicolumn{2}{|c|}{ CEAT: aderente estrito $(n=21)$} & \multicolumn{2}{|c|}{ CEAT: boa adesão $(n=16)$} & \multicolumn{2}{|c|}{ CEAT: pouco aderente $(n=14)$} & \multirow{2}{*}{ Teste } & \multirow{2}{*}{$\mathrm{p}$-valor } \\
\hline & Media (DP) & Mediana (mín-max) & Media (DP) & Mediana (mín-max) & Media (DP) & Mediana (mín-max) & & \\
\hline \multirow{3}{*}{ Abertura } & $5,05(0,62)$ & $5,06(4,08-6,69)$ & $5,2(0,75)$ & $5,35(3,99-6,18)$ & $4,75(1,06)$ & $4,6(3,06-6,42)$ & Levene & 0,035 \\
\hline & \multirow{2}{*}{\multicolumn{4}{|c|}{$\begin{array}{l}\text { Comparações múltiplas: } \\
\text { Teste não paramétrico de Tukey }\end{array}$}} & & \multirow{2}{*}{\multicolumn{2}{|c|}{ pouco aderente - aderente estrito }} & 0,584 \\
\hline & & & & & & & & 0,482 \\
\hline Liberalismo & $5,15(0,87)$ & $5,29(3,29-6,71)$ & $5,66(0,91)$ & $5,79(3,57-7)$ & $5,16(1,01)$ & $5,08(3,57-7)$ & Kruskal-Wallis & 0,173 \\
\hline Busca por Novidades & $4,72(0,92)$ & $4,67(2,67-6,67)$ & $4,94(0,99)$ & $5,33(2,5-6)$ & $4,39(1,21)$ & $4(3-6,67)$ & Kruskal-Wallis & 0,283 \\
\hline
\end{tabular}




\title{
ANEXO III
}

\section{TERMO DE CONSENTIMENTO LIVRE E ESCLARECIDO}

\author{
Dados de identificação do sujeito da pesquisa ou responsável \\ legal.
}

NOME:

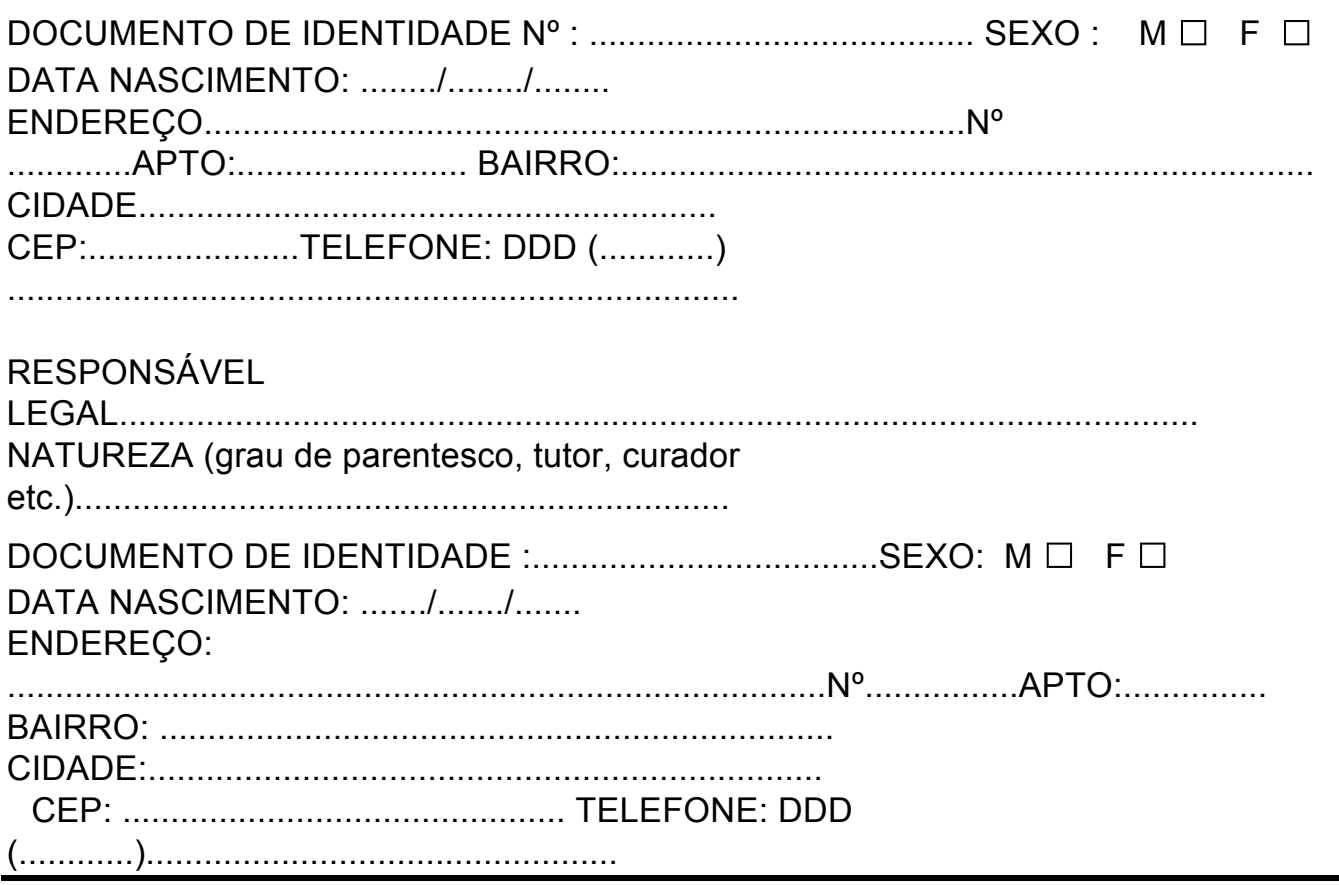

Avaliação do risco da pesquisa: Mínimo

\section{DADOS SOBRE A PESQUISA:}

Título do protocolo de pesquisa: Personalidade, Comportamento e Adesão ao tratamento em pacientes jovens infectados pelo HIV.

Pesquisador: Jorge Simão do Rosário Casseb

Cargo/função: Professor Doutor

Inscrição no Conselho Regional de Medicina: 67217

Unidade do HCFMUSP: Dermatologia - ADEE 3002

Avaliação do risco da Pesquisa:

Risco mínimo ( $\mathrm{x}$ ) Risco médio ( )

Risco baixo ( ) Risco maior ( )

Duração da Pesquisa: 1 ano

Rubrica do sujeito de pesquisa ou responsável:

Rubrica do pesquisador: 
Termo de consentimento livre e esclarecido para participação em pesquisa acadêmica.

(de acordo com a Resolução 196/96 do Conselho Nacional de Saúde-

$$
\text { Brasília - DF) }
$$

Você está sendo convidado a participar de uma pesquisa entitulada:

"Personalidade, Comportamento e Adesão ao tratamento em pacientes jovens infectados pelo HIV".

Sua participação é muito importante para que possamos investigar se existem algumas características de personalidade que possam estar associadas a uma melhor ou pior adesão ao seu tratamento.

Sua participação é completamente voluntária e você é livre para recusar caso não se sinta à vontade para participar.

Caso você opte por participar, a pesquisa consistirá na realização de uma entrevista e aplicação de 4 questionários:

1) Entrevistas com questões sobre dados demográficos e clínicos como idade, sexo, adoecimentos atuais e pré existentes, medicações em uso atualmente, dentre outros;

2) questionário sobre o uso atual ou anterior de álcool, tabaco e outras substâncias;

3) Bateria Fatorial de Personalidade

4) Questionário de Avaliação para Adesão ao Tratamento Antiretroviral

A aplicação dos questionários acontecerá em uma sala localizada no Hospital das Clínicas com duração aproximada de 60 minutos. A pesquisa apresenta risco mínimo aos participantes, ou seja, você pode ficar cansado durante a aplicação dos testes. Caso isso ocorra, por favor avise o avaliador.

As informações obtidas são sigilosas e seu nome não será revelado.

O dia e horário para a realização das atividades acima será combinado anteriormente com você e, caso queira desistir da pesquisa a qualquer momento, você não será prejudicado nos atendimentos em qualquer serviço deste hospital.

Caso haja alguma dúvida, sinta-se à vontade para falar conosco entrando em contato com os pesquisadores pelos números de telefones: 982282569(Lívia Bueno), 98338-4661 (Dr. Jorge), 98686-9602 (Maria Rita) ou Comitê de Ética em Pesquisa: Tel: 38961406

Mais uma vez, estamos à disposição para quaisquer esclarecimentos.

Lívia Maria de A. C Bueno

Dr. Jorge Casseb

Psicóloga CRP 06/94345

Médico CRM 63475 
$\mathrm{Eu}$, li e entendi (ou alguém me explicou) as informações contidas neste termo de consentimento, e todas as minhas dúvidas foram esclarecidas, e concordo em participar da pesquisa intitulada "Personalidade, Comportamento e Adesão ao tratamento em pacientes jovens infectados pelo HIV" e que recebi 1 (uma) cópia do presente termo de consentimento.

Nome do Voluntário (letra de forma)

Assinatura do voluntário

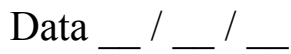

Nome de quem obteve o consentimento(letra de forma)

Assinatura de quem obteve o consentimento

Data 


\section{ANEXO IV}

\section{DADOS DEMOGRÁFICOS E CLÍNICOS}

- Identificação do paciente

- Sexo: ( M ) ( F )

- Idade (anos):

- Naturalidade / Procedência:

- Anos completos de educação:

- Doenças sistêmicas / metabólicas prévias ou atuais (especificar):

- Doenças neuropsiquiátricas prévias ou atuais (especificar):

- Data do diagnóstico de infecção pelo HIV:

- Mecanismo de transmissão da infecção pelo vírus:

- Doenças prévias ou atuais:

- Esquema de medicação atual:

- Profilaxias em uso:

- Outros medicamentos (excluindo aqueles para tratar neuropatia periférica):

- Última contagem de células CD4+ (data):

- Última quantificação da carga viral plasmática do HIV-1 (data 


\section{ANEXO V}

\section{ASSIST - Questionário para Triagem do Uso de Álcool, Tabaco e Outras Substâncias}

Esta avaliação consiste em 8 questões. Depois de ler cuidadosamente cada grupo de idéias, faça um círculo em torno do número $(0,1,2,3,4)$ que melhor descreva sua realidade em relação ao uso de drogas psicoativas. Tome cuidado de ler todas as afirmações, em cada questão, antes de fazer a sua escolha.

Nome: Registro:

Entrevistador: Data:

\section{Na sua vida qual(is) substância(s) você já usou (somente uso não prescrito} pelo médico)

a.derivados do tabaco

b.bebidas alcoólicas

c. maconha

d. cocaína, crack

e. anfetaminas ou êxtase

f. inalantes

g. hipnóticos/sedativos

h. alucinógenos

i. opióides

j. outras, especificar

\begin{tabular}{|c|c|}
\hline NÃO & SIM \\
\hline 0 & 2 \\
\hline 0 & 2 \\
\hline 0 & 2 \\
\hline 0 & 2 \\
\hline 0 & 2 \\
\hline 0 & 2 \\
\hline 0 & 2 \\
\hline 0 & 2 \\
\hline 0 & 2 \\
\hline 0 & 2 \\
\hline
\end{tabular}

- Se "NÃO" em todos os itens investigue: Nem mesmo quando estava na escola?

- Se "NÃO" em todos os itens, pare a entrevista

- Se "SIM" para alguma droga, continue com as demais questões

\begin{tabular}{|l|c|c|c|c|c|}
\hline $\begin{array}{l}\text { 2. Durante os três últimos meses, com que } \\
\text { freqüência você utilizou essa(s) } \\
\text { substância(s) que mencionou? (primeira } \\
\text { droga, depois a segunda droga, etc) }\end{array}$ & Nunca & $\begin{array}{l}\text { 1 ou 2 } \\
\text { vezes }\end{array}$ & Mensal & Semanal & $\begin{array}{l}\text { Diário ou } \\
\text { quase } \\
\text { todos os } \\
\text { dias }\end{array}$ \\
\hline a.derivados do tabaco & 0 & 1 & 2 & 3 & 4 \\
\hline b.bebidas alcóolicas & 0 & 1 & 2 & 3 & 4 \\
\hline c. maconha & 0 & 1 & 2 & 3 & 4 \\
\hline d. cocaína, crack & 0 & 1 & 2 & 3 & 4 \\
\hline e. anfetaminas ou êxtase & 0 & 1 & 2 & 3 & 4 \\
\hline f. inalantes & 0 & 1 & 2 & 3 & 4 \\
\hline g. hipnóticos/sedativos & 0 & 1 & 2 & 3 & 4 \\
\hline h. alucinógenos & 0 & 1 & 2 & 3 & 4 \\
\hline i. opióides & 0 & 1 & 2 & 3 & 4 \\
\hline j. outras, especificar & 0 & 1 & 2 & 3 & 4 \\
\hline
\end{tabular}

- Se "NUNCA" em todos os itens da questão 2 pule para a questão 6, com outras respostas continue com as demais questões 


\begin{tabular}{|l|c|c|c|c|c|}
\hline $\begin{array}{l}\text { 3. Durante os três últimos meses, com que } \\
\text { freqüência você teve um forte desejo ou } \\
\text { urgência de consumir? (primeira droga, } \\
\text { depois a segunda droga, etc) }\end{array}$ & Nunca & $\begin{array}{l}\text { 1 ou 2 } \\
\text { vezes }\end{array}$ & Mensal & Semanal & $\begin{array}{l}\text { Diário ou } \\
\text { quase } \\
\text { todos os } \\
\text { dias }\end{array}$ \\
\hline a.derivados do tabaco & 0 & 1 & 2 & 3 & 4 \\
\hline b.bebidas alcóolicas & 0 & 1 & 2 & 3 & 4 \\
\hline c. maconha & 0 & 1 & 2 & 3 & 4 \\
\hline d. cocaína, crack & 0 & 1 & 2 & 3 & 4 \\
\hline e. anfetaminas ou êxtase & 0 & 1 & 2 & 3 & 4 \\
\hline f. inalantes & 0 & 1 & 2 & 3 & 4 \\
\hline g. hipnóticos/sedativos & 0 & 1 & 2 & 3 & 4 \\
\hline h. alucinógenos & 0 & 1 & 2 & 3 & 4 \\
\hline i. opióides & 0 & 1 & 2 & 3 & 4 \\
\hline j. outras, especificar & 0 & 1 & 2 & 3 & 4 \\
\hline
\end{tabular}

\begin{tabular}{|l|c|c|c|c|c|}
\hline $\begin{array}{l}\text { 4. Durante os três últimos meses, com que } \\
\text { freqüência o seu consumo de (primeira } \\
\text { droga, depois a segunda droga, etc) } \\
\text { resultou em problema de saúde, social, } \\
\text { legal ou financeiro? }\end{array}$ & $\begin{array}{l}\text { 1 ou 2 } \\
\text { vezes }\end{array}$ & Mensal & Semanal & $\begin{array}{l}\text { Diário ou } \\
\text { quase } \\
\text { todos os } \\
\text { dias }\end{array}$ \\
\hline a.derivados do tabaco & 0 & 1 & 2 & 3 & 4 \\
\hline b.bebidas alcóolicas & 0 & 1 & 2 & 3 & 4 \\
\hline c. maconha & 0 & 1 & 2 & 3 & 4 \\
\hline d. cocaína, crack & 0 & 1 & 2 & 3 & 4 \\
\hline e. anfetaminas ou êxtase & 0 & 1 & 2 & 3 & 4 \\
\hline f. inalantes & 0 & 1 & 2 & 3 & 4 \\
\hline g. hipnóticos/sedativos & 0 & 1 & 2 & 3 & 4 \\
\hline h. alucinógenos & 0 & 1 & 2 & 3 & 4 \\
\hline i. opióides & 0 & 1 & 2 & 3 & 4 \\
\hline j. outras, especificar & 0 & 1 & 2 & 3 & 4 \\
\hline
\end{tabular}

\begin{tabular}{|l|c|c|c|c|c|}
\hline $\begin{array}{l}\text { 5. Durante os três últimos meses, com que } \\
\text { freqüência por causa do seu uso (primeira } \\
\text { droga, depois a segunda droga, etc) você } \\
\text { deixou de fazer coisas que eram } \\
\text { normalmente esperadas de você? }\end{array}$ & $\begin{array}{l}\text { 1 ou 2 } \\
\text { vezes }\end{array}$ & Mensal & Semanal & $\begin{array}{l}\text { Diário ou } \\
\text { quase } \\
\text { todos os } \\
\text { dias }\end{array}$ \\
\hline a.derivados do tabaco & 0 & 1 & 2 & 3 & 4 \\
\hline b.bebidas alcóolicas & 0 & 1 & 2 & 3 & 4 \\
\hline c. maconha & 0 & 1 & 2 & 3 & 4 \\
\hline d. cocaína, crack & 0 & 1 & 2 & 3 & 4 \\
\hline e. anfetaminas ou êxtase & 0 & 1 & 2 & 3 & 4 \\
\hline f. inalantes & 0 & 1 & 2 & 3 & 4 \\
\hline g. hipnóticos/sedativos & 0 & 1 & 2 & 3 & 4 \\
\hline h. alucinógenos & 0 & 1 & 2 & 3 & 4 \\
\hline i. opióides & 0 & 1 & 2 & 3 & 4 \\
\hline j. outras, especificar & 0 & 1 & 2 & 3 & 4 \\
\hline
\end{tabular}


FAÇA as questões 6 e 7 para todas as substâncias mencionadas na questão 1

\begin{tabular}{|l|c|c|c|c|c|}
\hline $\begin{array}{l}\text { 6. Há amigos, parentes ou outra pessoa } \\
\text { que tenha demonstrado preocupação } \\
\text { com o uso de (primeira droga, depois a } \\
\text { segunda droga, etc)? }\end{array}$ & $\begin{array}{l}\text { 1 ou 2 } \\
\text { vezes }\end{array}$ & Mensal & Semanal & $\begin{array}{l}\text { Diário ou } \\
\text { quase } \\
\text { todos os } \\
\text { dias }\end{array}$ \\
\hline a.derivados do tabaco & 0 & 1 & 2 & 3 & 4 \\
\hline b.bebidas alcóolicas & 0 & 1 & 2 & 3 & 4 \\
\hline c. maconha & 0 & 1 & 2 & 3 & 4 \\
\hline d. cocaína, crack & 0 & 1 & 2 & 3 & 4 \\
\hline e. anfetaminas ou êxtase & 0 & 1 & 2 & 3 & 4 \\
\hline f. inalantes & 0 & 1 & 2 & 3 & 4 \\
\hline g. hipnóticos/sedativos & 0 & 1 & 2 & 3 & 4 \\
\hline h. alucinógenos & 0 & 1 & 2 & 3 & 4 \\
\hline i. opióides & 0 & 1 & 2 & 3 & 4 \\
\hline j. outras, especificar & 0 & 1 & 2 & 3 & 4 \\
\hline
\end{tabular}

\begin{tabular}{|l|c|c|c|c|c|}
\hline $\begin{array}{l}\text { 7. Alguma vez você já tentou controlar, } \\
\text { diminuir ou para o uso de (primeira } \\
\text { droga, depois a segunda droga, etc) e não } \\
\text { conseguiu? }\end{array}$ & $\begin{array}{l}\text { 1 ou 2 } \\
\text { vezes }\end{array}$ & Mensal & Semanal & $\begin{array}{l}\text { Diário ou } \\
\text { quase } \\
\text { todos os } \\
\text { dias }\end{array}$ \\
\hline a.derivados do tabaco & 0 & 1 & 2 & 3 & 4 \\
\hline b.bebidas alcóolicas & 0 & 1 & 2 & 3 & 4 \\
\hline c. maconha & 0 & 1 & 2 & 3 & 4 \\
\hline d. cocaína, crack & 0 & 1 & 2 & 3 & 4 \\
\hline e. anfetaminas ou êxtase & 0 & 1 & 2 & 3 & 4 \\
\hline f. inalantes & 0 & 1 & 2 & 3 & 4 \\
\hline g. hipnóticos/sedativos & 0 & 1 & 2 & 3 & 4 \\
\hline h. alucinógenos & 0 & 1 & 2 & 3 & 4 \\
\hline i. opióides & 0 & 1 & 2 & 3 & 4 \\
\hline j. outras, especificar & 0 & 1 & 2 & 3 & 4 \\
\hline
\end{tabular}

Nota Importante: Pacientes que tenham usado drogas injetáveis nos últimos 3 meses devem ser perguntados sobre seu padrão de uso injetável durante este período, para determinar seus níveis de risco e a melhor forma de intervenção.

\begin{tabular}{|l|l|l|l|}
\hline $\begin{array}{l}\text { 8. Alguma vez já usou drogas por injeção? } \\
\text { (Apenas uso não médico) }\end{array}$ & $\begin{array}{l}\text { NÂO, } \\
\text { nunca } \\
0\end{array}$ & $\begin{array}{l}\text { SIM, nos últimos } \\
3 \text { meses } \\
1\end{array}$ & $\begin{array}{l}\text { SIM, mas não } \\
\text { últimos } 3 \text { meses } \\
2\end{array}$ \\
\hline
\end{tabular}


PONTUAÇÃO PARA CADA DROGA

\begin{tabular}{|l|l|l|l|l|}
\hline & $\begin{array}{l}\text { Anote a pontuação para cada } \\
\text { droga. SOME SOMENTE das } \\
\text { questões 2,3,4,5,6 e 7 }\end{array}$ & $\begin{array}{l}\text { Uso } \\
\text { ocasional }\end{array}$ & $\begin{array}{l}\text { Sugestivo } \\
\text { de Abuso }\end{array}$ & $\begin{array}{l}\text { Sugestivo de } \\
\text { Dependência }\end{array}$ \\
\hline Tabaco & & $0-3$ & $4-15$ & $16-20$ \\
\hline Alcool & & $0-3$ & $4-15$ & $16-20$ \\
\hline Maconha & & $0-3$ & $4-15$ & $16-20$ \\
\hline Cocaína & & $0-3$ & $4-15$ & $16-20$ \\
\hline Anfetaminas & & $0-3$ & $4-15$ & $16-20$ \\
\hline Inalantes & & $0-3$ & $4-15$ & $16-20$ \\
\hline Hipnóticos/sedativos & & $0-3$ & $4-15$ & $16-20$ \\
\hline Alucinógenos & & $0-3$ & $4-15$ & $16-20$ \\
\hline Opiódes & & $0-3$ & $4-15$ & $16-20$ \\
\hline
\end{tabular}

Nomes Populares ou Comerciais das Drogas

a. produtos do tabaco ( cigarro, charuto, cachimbo, fumo de corda)

b. bebidas alcoólicas (cerveja, vinho, champagne, licor, pinga, uísque, vodca, vermutes, caninha, rum, tequila, gin)

c. maconha (baseado, erva, liamba, birra, fuminho, fumo, mato, bagulho, pango, manga-rosa, massa, haxixe, Skank, etc)

d. cocaína, crack (coca, pó, branquinha, nuvem, farinha, neve, pedra, caximbo, brilho)

e. estimulantes como anfetaminas (bolinhas, rebites, bifetamina, moderine, MDMA)

f. inalantes ( solventes, cola de sapateiro, tinta, esmalte, corretivo, verniz, tinner, clorofórmio, tolueno, gasolina, éter, lança perfume, cheirinho de loló)

g. hipnóticos, sedativos ( ansioolóticos, tranqüilizantes, barbitúricos, fenobarbital, pentobarbital, benzodiazepínicos, diazepam)

h. alucinógenos ( LSD, chá de lírio, ácido, passaporte, mescalina, peiote, cacto)

i. opiáceos( morfina, codeína, heroína, elixir, metadona)

j. outras: especificar 


\section{ANEXO VI \\ Questionário para a Avaliação da Adesão ao Tratamento Antiretroviral em Pessoas com Infecção pelo HIV e Aids (CEAT-VIH, Versão brasileira 2.0)}

Data de avaliação:

Nome completo:

Data de nascimento:

Nível de estudos:

Centro:

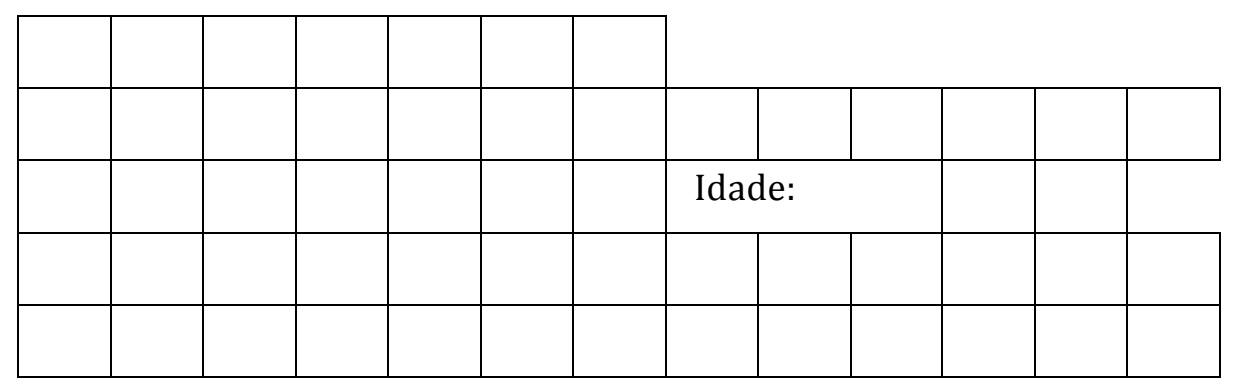

Instruções: Gostariamos de conhecer algunos aspectos sobre a sua situação atual e sobre seu tratamento. A informação que você proporcione será estrictamente confidencial. Por favor, responda a todas as perguntas pessoalmente. Marque a opção que melhor se adecue ao seu caso e lembre-se de que não há respostas "certas" ou "erradas".

Durante a última semana

1. Deixou de tomar sua medicação alguma vez?

2. Se alguma vez sentiu-se melhor, deixou de tomar sua medicação?

3. Se alguma vez depois de tomar sua medicação sentiu-se pior, deixou de tomá-la? 4. Se alguma vez se sentiu triste ou deprimido, deixou de tomar sua medicação?

5. Lembra-se que remédios está tomando nesse momento?

(escrever os nomes) das das vezes

vezes
Sempre

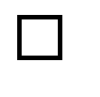

\section{$\square$}
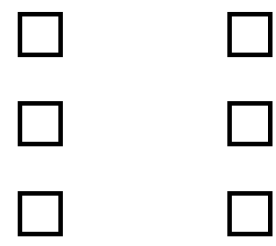

Nenhuma vez
Alguma

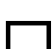

6. Como é a relação que mantém com o seu médico?

Um pouco ruim
Regular
Pode melhorar

Boa
Nada Pouco Regular Bastant Muito

7. Quanto esforçovocê faz para seguir (cumprir) com o seu tratamento?

8. Quanta informação você tem sobre os medicamentos que toma para o HIV?

9. Quanto benefício pode lhe trazer o uso destes medicamentos?

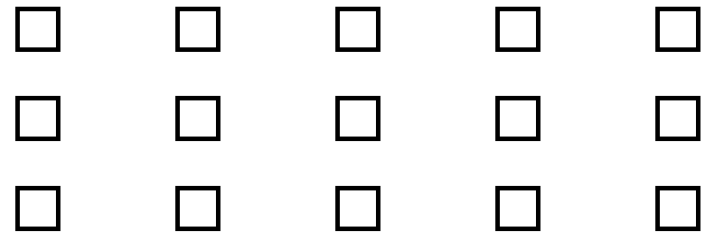


10. Considera que sua saúde melhorou desde que começou a tomar os medicamentos para o HIV?

11. Até que ponto sente-se capaz de seguir com o tratamento?

$\begin{array}{lllll}\begin{array}{l}\text { Não, } \\ \text { nunca }\end{array} & \begin{array}{l}\text { Sim, } \\ \text { alguma } \\ \text { vez }\end{array} & \begin{array}{l}\text { Sim, } \\ \text { aproxi } \\ \text { madam } \\ \text { ente a } \\ \text { metade } \\ \text { das } \\ \text { vezes }\end{array} & \begin{array}{l}\text { Sim, } \\ \text { muitas }\end{array} & \begin{array}{l}\text { Sim, } \\ \text { sempre }\end{array} \\ \square & \square & \square & \square & \square \\ \square & \square & \square & \square & \square\end{array}$

12. Normalmente está acostumado a tomar a medicação na hora certa?

13. Quando os resultados dos exames são bons, seu médico costuma utilizá-los para lhe dar ânimo e motivação para seguir com o tratamento?

14. Como sente-se em geral com o tratamento desde que começou a tomar seus remédios?

\begin{tabular}{|l|l|l|l|l|}
\hline Muito insatisfeito & Insatisfeito & Indiferente & Satisfeito & Muito satisfeito \\
\hline
\end{tabular}

15. Como avalia a intensidade dos efeitos colaterais relacionados com o uso dos medicamentos para o HIV?

\begin{tabular}{|l|l|l|l|l|}
\hline Muito intensos & Intensos & $\begin{array}{l}\text { Medianamente } \\
\text { intensos }\end{array}$ & Pouco intensos & Nada intensos \\
\hline
\end{tabular}

16. Quanto tempo acredita que perde ocupando-se em tomar seus remédios?

\begin{tabular}{|l|l|l|l|l|}
\hline Muito tempo & Bastante tempo & Regular & Pouco tempo & Nada de tempo \\
\hline
\end{tabular}

17. Que avaliação tem de si mesmo com relação a toma dos remédios para o HIV?

\begin{tabular}{|l|l|l|l|l|}
\hline Nada cumpridor & Pouco cumpridor & Regular & Bastante & Muito cumpridor \\
\hline
\end{tabular}

18. Quanta dificuldade tem para tomar a medicação?

\begin{tabular}{|l|l|l|l|l|}
\hline Muita dificuldade & $\begin{array}{l}\text { Bastante } \\
\text { dificuldade }\end{array}$ & Regular & Pouca dificuldade & $\begin{array}{l}\text { Nenhuma } \\
\text { dificuldade }\end{array}$ \\
\hline
\end{tabular}

19. Desde que está em tratamento alguma vez deixou de tomar sua medicação um
dia completo, ou mais de um?
[Se responde afirmativamente, Quantos dias aproximadamente?] .....................
20. Utiliza alguma estratégia para lembrar-se de tomar a medicação?
Qual?




\section{ANEXO VII}

\section{BFP \\ CCM.03.13 \\ Bateria Fatorial de Personalidade \\ Carlos Henrique Nunes \\ Claudio Hutz \\ Maiana Farias Oliveira Nunes}

\section{Caderno de Aplicação}

\section{Instruções:}

Você está recebendo um caderno que contém frases que descrevem sentimentos, opiniōes e atitudes. Por favor, leia atentamente cada uma das sentenças e pense o quanto vocé se identifica com elas. A seguir, marque no Protocolo de Respostas, no local apropriado, a sua resposta a cada item.

Para tanto, siga as instruções abaixo:

Para cada item, você tem a opçào de marcar de "1" a "7". Se vocé acha que a sentença absolutamente não o descreve adequadamente, marque " 1 ". Se você acha que a frase o descreve muito bem, marque o "7" no Protocolo de Respostas. Se você considerar que a frase o descreve "mais ou menos", marque "4".

Considere que quanto mais você acha que a frase é apropriada para descrevê-lo, maior deve ser o valor a ser marcado na escala (respostas 5, 6 e 7); quanto menos vocé identificar-se com a descrição feita, menor será o valor a ser registrado na escala (respostas 1, 2 e 3). Note que todos os valores da escala podem ser marcados.

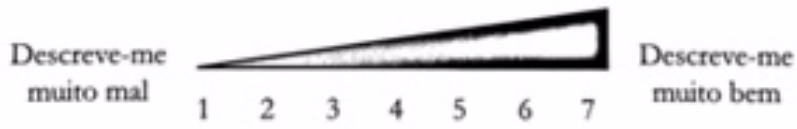

Não existem respostas certas ou erradas. É importante que suas respostas sejam sinceras. Responda a todos os itens e, por favor, não risque ou escreva no caderno de aplicação. 


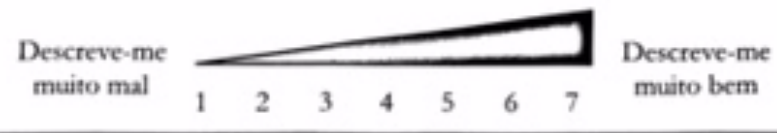

1. Procuro seguir as regras sociais sem questioni-las

2. Tento fazer com que as pessoas se sintam bem.

3. Gosto de falar sobre mim.

4. Tenho um "coraçlo mole".

5. Falo tudo o que penso.

6. Gosto de fazer coisas que nunca fiz antes.

7. Acredito que as pessoas tềm boas intençòes.

8. Sou divertida.

9. Tomo cuidado com o que fala

10. Dificilmente perdoo.

11. Divirto-me quando estou entre muitas pessoas.

12. Respeito os sentimentos alheiox

13. Mesmo quando preciso resolver algurna coisa para mim, costumo adiar até o último momenta

14. Tento influenciar os outros.

15. Sou generoso(a).

16. Estou satisfeito comigo mesmo(a).

17. Nìo falo muito.

18. Posso agredir fisicamente as pessoas quando fico muito irritado.

19. Resolvo meus problemas sem pensar muita.

20. Preocupo-me com todos.

21. Geralmente me sinto feliz.

22. Preciso de estimulo para começar a fazer as coisas.

23. Tenho pouco interesse por exposicòes de arte.

24. Divirto-me contrariando as pessoas.

25. Com frequéncia tomo decisōes precipitadas.

26. Facilmente coloco as minhas ideias em prática.

27. Uso as pessoas para conseguir o que desejo.

28. Posso lidar com muitas tarefas ao mesmo tempo.

29. Quase sempre me sinto desanimada.

30. Suspeito das intençò̀es das pessoas.

31. Atualmente, defendo ideias diferentes daquelas que defendia antigamente.

32. Consigo o que eu quera.

33. Tenho pouca curiosidade para conhecer nowos estilos musicais.

34. Dedico-me muito para fazer bem as coisas.

35. Espero pela decisào dos outros.

36. Interesso-me por teorias que tentam explicar o universo.

37. Tenho pouca paciència para terminar tarefas muito longas ou dificeis.

38. Sou uma pessoa tímida.

39. Tenho alguns inimigos.

40. Acho que a minha vida é vazia e sem emoçàa

41. Começo rapidamente as tarefas que tenho para fazer.

42. Acho pouco interessantes exposiçõ̃es fotograficas.

43. Respeito o ponto de vista dos outros.

44. Tenho dificuldade para me adaptar a trabalhos que envolvam uma rotina fixa.

45. Antes de agir, penso no que pode acontecer. 


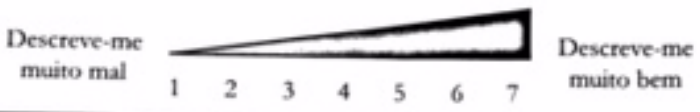

46. Sinto-me mal se nio cumpro algo que prometi.

47. Adoro atividades em grup̣o

48. Tudo o que posso ver a minha frente é mais desprazer do que prazer.

49. Gosto de ir a lugares que nio conheço.

50. Coaverso com muitas pessoas diferentes quando vou a festas.

51. Ajo impulsivamente quando alguma coisa está me aborrecendo.

52. Gosto de ter uma vida social agitada.

53. Participar de atividades que envolvam criatividade e/ou fantasia me empolga.

54. Me esforço para ter destaque na escola ou no trabalho

55. Geralmente faço o que os meus amigos e patentes querem, embora nào concorde com eles, com medo de que se afastem de mim.

56. Tenho pouco interesse por ideias abstratas

57. Acho que os outros zombam de mim.

58. Costumo fazer sacrificios para conseguir o que quero.

59. Acho natural que os valores morais mudem ao longo do tempo

60. Tenho muito medo de que os meus amigos deixem de gostar de mim.

61. Tento incentivar as pessoas.

62. Sou uma pessoa com pouca imaginaçio.

63. Faço coisas consideradas perigosas.

64. Penso sobre o que preciso fazer para alcançar meus objetivos.

65. Sou uma pessoa nervosa.

66. Costumo ficar calado quando estou entre estranhos.

67. Resolvo meus problemas com rapidez.

68. Confio no que as pessoas dixem.

69. Acho que nào existe uma verdade absoluta.

70. Por mais que me esforce, sei que nào sou capaz de superar os obstículos que tenho que enfrentar no dia a dia.

71. Envolvo-me rapidamente com os outros.

72. Gosto de pensar sobre soluçōes diferentes para problemas complexos.

73. Deixo de fazer as coisas que descjo por medo de ser criticado pelos outros.

74. Acredito que a maioria dos valores morais sào dependentes da época $e$ do lugat

75. Fico muito tímido quando estou entre desconhecidos.

76. Preocupo-me em agir segundo as leis.

77. Meu humor varia constantemente.

78. Necessito estar no centro das atençòes.

79. Sinto-me muito inseguro quando tenho que fazer coisas que nunca fiz antes.

80. As pessoas dizem que sou muito detalhista.

81. Evito discussōes filosóficas.

82. Nào gosto de expressar as minhas ideias, pois tenho medo de ser ridicularizado

83. Sou capaz de assumir tarefas importantes.

84. Gosto de manter a rotina.

85. Acho que faço bem as coisas.

86. Sou uma pessoa irritável.

87. Costumo enganar as pessoas.

88. Gosto de trabalhos artísticos que sào considerados estranhos. 


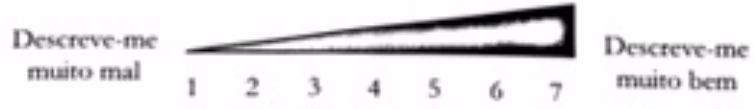

89. Tenho muita dificuldade em tomar decisòes na minha vida.

90. Vivo minhas emoçòes intensamente.

91. Gosto de faser coisus que exigem muito de mìm.

92. Sofro quando encontro alguém que está com dificuldades.

93. Ê comum terem inveja de mim.

94. Sempre que posso, mudo os trajetos nos meus percursos diánios.

95. Tenho dificuldade para terminar as tarefas, pois me distraio com outras coisas

96. Preocupo-me com aqueles que estìo numa situaçào pior que a minha.

97. Sou comunicativo

98. Acho que os outros podem tentar me prejudicar.

99. Sinto uma incontrolivel vontade de falar, mesmo que seja com quem nào conheço

100. Eu paro de fazer as coisas quando elas ficam muito dificeis.

101. Escolho as palavras com cuidado

102. Com frequéncia, passo por periodos em que fico extremamente irritível, incomodando-me com qualquer coisa.

103. Raramente mostro um trabalho a outras pessoas antes de revisá-lo cuidadosamente.

104. Importo-me com os sentimentos dos outros.

105. Faço muitas coisas durante as minhas horas de folga.

106. Estou cansado de viver.

107. Gosto de quebrat regras.

108. Costumo tomar a iniciativa e conversar com os outros.

109. Respeito autoridades.

110. Sou uma pessoa insegura.

111. Quando estou entre um grupo, gosto que me deem atençàa

112. Meus amigos dizem que cu trabalho/estudo demais.

113. Sinto-me entediado quando tenho que fazer as mesmas coisas.

114. Exijo muito de mim mesma.

115. Tenho dificuldade para participar de atividades que exijam imaginaçìo ou fantasia.

116. Gosto de programar detalhadamente as coisas que tenho para fazer.

117. Usualmente, tomo a iniciativa nas situaçōes.

118. Sinto-me muito mal quando recebo alguma crítica.

119. Acredito que as pessoas tém uma natureza ruim.

120. Dificilmente fico sem jeito.

121. Só me aproximo de uma pessoa quando estou certo de que ela concorda com as minhas opiniồes

e atitudes, para evitar críticas ou desaprovaçio.

122. Sei o que quero para minha vida.

123. Frequentemente questiono regras e costumes sociais.

124. Tenho uma grande dificuldade em dormir.

125. Preocupo-me em agradar as pessoas.

126. Sou disposto a rever meus posicionamentos sobre diferentes assuntos.

U11 2013 Canapai Livraria o Edarora Lida

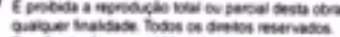

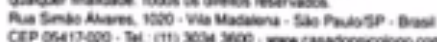

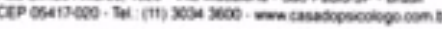




\title{
ANEXO VIII
}

\author{
Hospital das Clínicas da FMUSP
}

Comissão de Ética para Análise de Projetos de Pesquisa - CAPPesq

\section{PROJETO DE PESQUISA}

Título: PERSONALIDADE, COMPORTAMENTO E ADESÃO AO TRATAMENTO EM PACIENTES JOVENS INFECTADOS PELO HIV

Pesquisador Responsável: Jorge Casseb Versão:

Pesquisador Executante: Lívia Maria Cunha Bueno Villares CAAE: 22052814.9.0000.0068

da Costa

Finalidade Acadêmica Mestrado

Instituição: HCFMUSP

Departamento: DERMATOLOGIA

\section{PARECER CONSUBSTANCIADO DO CEP}

Registro on-line: 11435

Número do Parecer: 673.917

Data da Relatoria: 04/06/2014

Apresentação do Projeto: O projeto intitulado Personalidade, Comportamento e Adesão ao tratamento em pacientes jovens infectados pelo HIV tem finalidade acadêmica (mestrado). O protocolo será desenvolvido no HC FMUSP, incluindo entrevistas (quatro tipo de questionários) e análise de prontuários médicos dos mesmos pacientes. Mais especificamente o estudo ocorrerá no Núcleo de Imunodeficiências Secundárias (NIS): ambulatório (ADEE 3002) de pacientes infectados pelo HIV dentro do Hospital das Clínicas da Faculdade de Medicina da Universidade de São Paulo.

Objetivo da Pesquisa: O protocolo tem o objetivo de avaliar a existência de correlação entre Adesão ao tratamento para HIV e Personalidade em pacientes adultos jovens infectados.Três objetivos secundários estão inscritos no protocolo:

1 - Avaliar traços de Personalidade de pacientes adultos jovens infectados pelo HIV.

2 - Identificar fatores de adesão/não adesão ao tratamento destes pacientes.

3 - Avaliar a existência de correlação entre os fatores citados acima.

Avaliação dos Riscos e Benefícios: Já descritos no parecer anterior (552.788).

Comentários e Considerações sobre a Pesquisa: Já descritos no parecer anterior (552.788)

Considerações sobre os Termos de apresentação obrigatória: Foram realizadas as alterações sugeridas - parecer anterior (552.788) - especialmente quanto à metodologia e ao TCLE de modo satisfatório.

Rua Dr. Ovídio Pires de Campos, 225 - Prédio da Administração - 5ำ andar

$$
\text { CEP 05403-010 - São Paulo - SP. }
$$

5511 2661-7585 - 5511 2661-6442 ramais: 16, 17, 18 | marcia.carvalho@hc.fm.usp.br 


\section{Hospital das Clínicas da FMUSP}

Comissão de Ética para Análise de Projetos de Pesquisa - CAPPesq

Recomendações: nenhuma

Conclusões ou Pendências e Lista de Inadequações: nenhuma

Situação do Parecer: Aprovado

Necessita Apreciação da CONEP: Não

Considerações Finais a critério do CEP: Em conformidade com a Resolução CNS no 466/12 - cabe ao pesquisador: a) desenvolver o projeto conforme delineado; b) elaborar e apresentar relatórios parciais e final; c)apresentar dados solicitados pelo CEP, a qualquer momento; d) manter em arquivo sob sua guarda, por 5 anos da pesquisa, contendo fichas individuais e todos os demais documentos recomendados pelo CEP; e) encaminhar os resultados para publicação, com os devidos créditos aos pesquisadores associados e ao pessoal técnico participante do projeto; f) justificar perante ao CEP interrupção do projeto ou a não publicação dos resultados.

São Paulo, 04 de Junho de 2014

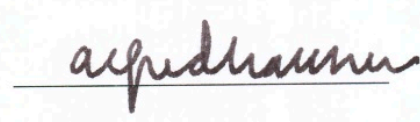

Prof. Dr. Alfredo José Mansur Coordenador

Comissāo de Ética para Análise de

Projetos de Pesquisa - CAPPesq

Rua Dr. Ovídio Pires de Campos, 225 - Prédio da Administração - 5a andar CEP 05403-010 - São Paulo - SP.

5511 2661-7585 - 5511 2661-6442 ramais: 16, 17, 18 | marcia.carvalho@hc.fm.usp.br 